\title{
Languaging in digital global South- North spaces in the twenty-first century: media, language and identity in political discourse
}

\author{
Sangeeta Bagga-Gupta ${ }^{*^{*}}$ (D) and Aprameya Rao ${ }^{2}$
}

*Correspondence:
sangeeta.bagga-gupta@ju.se
${ }^{1}$ School of Education
and Communication,
Jönköping University, P.O.
Box 1026,55111 Jönköping,
Sweden
Full list of author information
is available at the end of the
article

*Correspondence: sangeeta.bagga-gupta@ju.se and Communication, Jönköping University, P.O. Sweden

\begin{abstract}
Drawing inspiration from two theoretical framings: a sociocultural perspective on languaging and writings on a decolonial-turn, the study presented in this paper center-stages issues related to the need to engage analytically with, (i) social actions of political parties, citizens, including netizens in Web 2.0 settings, and (ii) alternative epistemologies where issues from the global-South are privileged. A central concern of decolonial linguistics enables asking new questions that destabilize established Eurocentric models of language. Thus, peripherally framed sociocultural premises contribute to critical social-humanistic perspectives that allow for (potentially) unpacking northern hegemonies and contributing to global-North challenges. Building upon an analytical design, this paper presents cross-disciplinary analysis of languaging in contemporary political mediascapes of the nation-states of India and Sweden. Bringing to bear that language does not only mirror reality, but is also a constitutive culturaltool, the study aims to highlight the contrastive ways in which the dominating political parties and citizens engage with languaging (i.e. the deployment of semiotic resources across language-varieties, modalities, including imagery). The study unpacks similarities and differences in salient issues related to the nature of social media and language and identity-positions in political discourse, highlighting dimensions of the participants voices. Thus, patterns that emerge from the contrastive analysis of political discourses, including the features of social media are highlighted and discussed. Data includes social media pages of two political parties from both the nation-states across a 6 -week period at the end of 2017.
\end{abstract}

Keywords: Global-South, Global-North, Sociocultural perspective, Decolonial, Languaging, Identity-positions, Political discourse, New social media, Ethnography

\section{Introduction}

"Some philosophers [...] have defined humans as essentially linguistic animals [others] as political animals [...] both definitions contain a germ of truth [...] political discourse analysts would probably claim [...] that the one definition necessarily involves the other" (Chilton and Schaffner 2011: 301).

The study presented here builds upon cross-disciplinary analysis of "languaging" (Linell 2009) or the meaning-making and deployment of semiotic resources in contemporary political mediascapes in the nation-states of India and Sweden (henceforth 
In and Sw). Far from being only a system of signs that express ideas or mirror intent, language-use or languaging (and discourse more broadly) is itself a constitutive cultural-tool (Berger and Luckmann 1966; Säljö 2010; Wertsch 1998). Going beyond a narrower understanding of language and taking a performatory stance on doing language, "Communication = Languaging = Meaning-making" (Bagga-Gupta and Dahlberg 2018) irrespective of the number of language-varieties or language-modalities (oral, written, signed, etc.) participants deploy across time and physical-digital practices (Bagga-Gupta 2017a, b, c, 2014). Recognizing that languaging/discourse "is what makes human cultures possible and unique" (Keating and Alessandro 2011: 331), the present study aims to raise issues regarding mundane political "ways-of-being-with-words" (Bagga-Gupta 2014) across global-South-North (henceforth GSN) spaces. More specifically, we focus on how new social media enable (or curtail) the participation of political parties, leaders and netizens. More specifically, the study looks at the ways in which the two largest political parties in In and Sw, including their citizenship (and other potential internet users), "language", i.e. participate in mediascapes. By focusing upon the mundane nature of languaging across a 6-week period, the study unpacks similarities and differences with regards to the nature of the media itself, languaging and identity-positions in political discourse.

In addition to a sociocultural perspective on languaging and discourse, this study draws upon issues of hegemony and colonial framings ("Sociocultural perspectives and decoloniality as complementary analytical lenses" section) by focusing upon ideologies related to identity, nation-states and language. Global-South spaces are either overshadowed by global-North ideologies or deprived of agency in much of the scholarship on languaging and discourse. The contrastive design of this study, including our backgrounds, i.e. experiential histories (vis-à-vis knowledge about languagevarieties, political and cultural experiences from In and $\mathrm{Sw}$ ), allow for problematizing mainstream center-periphery assumptions in the scholarship. In addition to recognizing that alternative epistemologies are marginalized across time-space, the socioculturally oriented, decolonial perspective on media, identity and language presented here, also call for encompassing geopolitical spaces like Sw that are not commonly associated with colonial ninetieth and twentieth century powers (Bhabha 1994; Hasnain et al. 2013).

Inspired by Maldonado-Torres (2011) and others' writings on a decolonial-turn, this study center-stages issues related to the need to engage analytically with alternative epistemologies where concepts and issues from the global-South are privileged. Following Khubchandani (1997) and some of our own previous writings (see particularly BaggaGupta 2017a, b, 2013), this means, for instance, that a central concern of decolonial linguistics asks new questions that can potentially destabilize established Eurocentric models of language, media and identity. This is one way for scholarship to go beyond issues of northern hegemonies (Gramling 2016; Makoni 2012).

Another point of departure for the study presented here is acknowledging the increasing role that new mediascapes play across the globe, including the paucity of research that systematically studies the ways in which digitalization shapes human existence in 
global-South spaces in general (Narayan and Narayanan 2016), and the political playing field across GSN more specifically. This means that social actions of political parties, its members and netizens in Web 2.0 settings are relevant sites of engagement for analysis.

The rest of this introductory section further elaborates on the theoretical framing used here ("Sociocultural perspectives and decoloniality as complementary analytical lenses") and discusses media-types ("Media-types across spaces. Some perspectives on India and Sweden") before presenting methodological framings and the nature of the datasets deployed in this study ("Methodological framings and data"). The central "Discourse and mediascapes" section presents the analysis under three overlapping themes: nature of the media ("Media features, convergence and participation spaces"), identitypositionings in political mediascapes currently ("Identity-positionings in political social media") and, the nature of language in political social media ("Languaging features in social media"). The final section presents reflections on salient issues regarding the ways in which mediascapes enable and curtail new ways-of-being-with-words across GSN.

\section{Sociocultural perspectives and decoloniality as complementary analytical lenses}

A key premise in sociocultural perspectives is that communication or languaging or participation is a situated and distributed process (Lave and Wenger 1999; Vygotsky 1962; Wertsch 1998). This means that languaging-irrespective of whether the communication deploys one or more language-varieties/modalities (Bagga-Gupta 1995, 2012, 2014, 2017a, b; Gynne 2016; Messina Dahlberg 2015)—is (i) collaboratively achieved, and (ii) constitutes a significant dimension of the construction of human realities; communication is not a conduit that in some neutral sense transfers knowledge or mirrors reality.

A key theoretical idea that frames such an action oriented, sociocultural perspective builds also upon the mediational role attributed to cultural-tools that have emerged across time and are appropriated by humans individually (Säljö 2010; Wertsch 1998). The symbiotic relationship between cultural-tools and people in inter-action with one another, has resulted in scholars hyphenating concepts (as can be seen in our own writing here and previously). This points to the significance of a social lens and the irreducible inter-connections of people and tools. However, while the rich potentials and dimensions of communication in concert with intellectual and material tools (like paper-pencils, calculators, computers, the internet, etc., including language itself) are recognized, attention in data analysis of social-practices in the global-North (at least) has been dominated by an "oral language bias" (Bagga-Gupta 2012, 2017a, b) and by a "monolingual bias" (Gramling 2016). This means that complex, multilayered languaging behaviour is marginally emphasized in the study of meaning-making. Focusing upon data from digital mediascapes across the GSN, (potentially) enables going beyond both these biases since Web 2.0 sites are de facto not "merely" oral or monolingual in character (Crystal 2011; Jewitt 2009).

Furthermore, power differentials in social practices are centre-staged empirically in this study from a decolonial framing (Abu-Lughod 1991; Comaroff and Comaroff 2009; Connell 2014; Mignolo 2012; Quijano 2000). This represents a call for a new reflexivity where the need to engage in empirically framed research is highlighted (Bagga-Gupta 2013; Hasnain et al. 2013). This enables a move away from philosophically and/or autobiographically oriented colonially framed discussions and towards the illumination of 
the many ways-of-being-with-words from across settings. Here social practices that are-in global-North contexts-glossed as mono/bi/multi/trans-lingualism, mono/bi/ multimodality and nation-state aligned identity-positions, including super/hyper-diversity, can potentially be studied from alternative perspectives (Bagga-Gupta and Dahlberg 2018; Hasnain et al. 2013; Pavlenko 2003; Santos 2014; Savransky 2017). Such alternative perspectives need to be cognizant of the fact that participation in contemporary mediascapes is completely contingent upon access to technological and digital tools. This means that participation and access issues can be both including and excluding across GSN spaces.

Cultivating a decolonial imagination (Savransky 2017) implies going beyond the hegemonies of (i) namism where references to key postcolonial texts in the Anglo-Saxion scholarship circulate, and (ii) "academic branding" (Pavlenko 2018) where some neologisms have gained currency in the twenty-first century (Bagga-Gupta and Dahlberg 2018). Namism, including other "ISMs of oppression" (Rivers and Zotzmann 2017), have tended to fix issues of power differentials in terms of historically colonized places. Such strategies however risk cementing ideologies. Going beyond such framings, we argue for the need to recognize decolonial perspectives in terms of a paradigm where it is the here and now in all spaces-east/south and west/north, including physical-virtual-that are worthy of empirical scrutiny (Bagga-Gupta 2017a, 2018). Such a stance implies that analytical units-of-analysis cannot be reduced to bounded entities based upon "imagined" boundaries that demarcate and create communities, nations, individuals or languagevarieties/modalities (Andersson 1994; see "Methodological framings and data" section).

While the idea of a language being a bounded unit and monolingualism, inherent in the Eurocentric one-nation-one-language ideology, have been challenged repeatedly, they are particularly difficult to dislodge in global-North discourses where it gets normatively mapped onto a one-language-one-individual norm. This means that while "citizens" in Sw are designated a default monolingual identity-position, "immigrants" get positioned as bilinguals (irrespective of their language-repertoires). While the fallacy of such reasoning is increasingly acknowledged in some global-North scholarship, bi/ multi/translingualism (as well as translanguaging) at the individual level continues to be marked in terms of the exotic, not "normal". The study presented here focuses upon the ways in which both individuals and institutions like political parties' language in public mediascapes; it points towards the performative work that participants and institutions "do" with semiotic resources across GSN settings.

\section{Media-types across spaces. Some perspectives on India and Sweden}

Digital technologies, including the advent of the internet, have had major consequences for citizens and institutions like political groups, schools, etc. (Narayan and Narayanan 2016). Different media-newspapers, radio, television, social media and Web 2.0-have expanded the scope and nature of engagement between political parties, politicians and citizens, including netizens (Saleem and Stephan 2016). New media has opened interactional spaces that allow for the creation of new types of "affinity spaces" and assemblages (Gee 2005). Communities with different interests assemble in open and closed groups without ever having to meet in-real-life (henceforth IRL). While there is recognition in a general sense that already existing communities/institutions (like political 
parties) participation in mediascapes has transformed their discourses, there is little theoretically pushed empirical scholarship that substantiates this. "Theoretical research in understanding issues related to the new media environment [...] may help create systems of knowledge that may be conducive to generalization of findings" of relevance to lives across the GSN (Srivastava and Enakshi 2016: 42). Contributing to this gap is an explicit aim of the study presented here.

Digitalization generally and Web 2.0 platforms specifically have changed not only engagement patterns, but also how democracy plays out in everyday life (Narayan and Narayanan 2016). While participation is contingent upon access to digitalization tools in a very tangible sense, issues of engagement do not follow a linear, foreseeable, developmental trajectory. Such issues of access and participation have seen the emergence of an interest in the study of alternative digital political spaces (Schroeder 2016); here affinity spaces are potentially open for politicians, citizens and political parties, anywhere 24/7. This does not mean, however, that openness automatically results in universal access or inclusiveness. Openness implied in digitalization is simplistic and reductionist and technology cannot be viewed as an agent that makes individuals, institutions or nation-states more democratic. Given that technologies have "implications for patterns of sociality" (Ingstad and Whyte 2007: 20), it is necessary that research recognizes both the affordances and constraints that digitalization gives rise to. Such a stance calls for the scrutiny of the mundaneness of contexts of participation.

In terms of the volume of users, Asia and Europe account for double the number of users as compared to the rest of the world combined. Internet penetration in In and Asia (46\%) are considered to be an issue as compared to the economically developed Europe (where it stands at around 80\%). ${ }^{1}$ However, in terms of volume, Asia is estimated to have the highest number of netizens (over 1.9 billion), with Europe at 659 million. Internet penetration currently stands at about $36 \%$ (462 million users) in In ${ }^{2}$ up from $20 \%$ in the first decade of the twenty-first century (Crystal 2011); this is below the world average of $51 \%$. Social media sites have exploded in both In and Sw and statistics indicate that there is almost a $100 \%$ connectivity across the lifespan in Sw: $79 \%$ of 2 -year olds and over $50 \%$ of $76+$ year olds use the internet regularly for a wide range of activities. ${ }^{3}$ Social media has not only become a significant tool for political communication and campaigning in In, but is reported to have also led to a rise in young peoples' political awareness (Rahul 2016). It is also reported to have "reshaped the way people access political information" (Saleem and Stephan 2016: 84).

"Though the digital divide remains a stark reality of the Indian new media environment, it is not a static, one-dimensional disparity between those with access to new media technology and those without access" (Srivastava and Enakshi 2016: 28). For instance, In is ahead of the United States with a reported 240 million users of Facebook. However, this constitutes one of the lowest figures across the globe since this adds up to

\footnotetext{
${ }^{1}$ Internet World Statistics. http://internetworldstats.com/stats.htm. Accessed 25 January 2018.

2 Internet World Statistics-Asia. http://www.internetworldstats.com/asia/in.htm. Accessed 20 December 2017.

3 Swedes and the Internet (in Swedish). https://www.iis.se/fakta/svenskarna-och-internet-2017/. Accessed 30 December 2017.
} 
only $19 \%$ of the nation-states population (June 2017). While In is the largest market for Facebook, Facebook constitutes the most popular internet platform in Sw.

In addition to issues of penetration, language constitutes a key feature that shapes openness and access. A mere 10 language-varieties are reported to occupy over $80 \%$ of the internet (Crystal 2011). While English is reported to be the most popular internet language (496 million), Hindi, Gujarati and Swedish-three of the four language-varieties in the datasets analyzed in this study (English is the fourth) - are part of the category "other" language-varieties used on the internet (314 million) (ibid).

While the entry of Multinational Corporations into In in the 1990s led to the launch of several news channels, it was the internet boom, which provided platforms for direct communication between politicians and citizens (Bali 2017). The digital revolution had a similar impact in Sw. "Social media can serve as a new form of more targeted communication in order to capitalize on its interactive potential. Therefore, social media's main power can be seen in the inclusion of targeted communities with a possible element of feedback (through likes, comments, etc.)" (Saleem and Stephan 2016: 81). Having direct (potential) access to citizens, political parties and politicians no longer need to rely (only) on traditional media (Bali 2017). At the same time, new media potentially gives citizens direct access to political parties and politicians (Narasimhamurthy 2014). Today, mediascapes like Facebook and Twitter have become the first sources of information about a politicians' day-to-day activities across the globe.

Web 2.0 platforms like Facebook enable anyone with an internet connection and a Facebook membership to participate both as consumers and as online producers of content. The virtual spaces of Facebook support pictures, videos, different scripts, emoticons/emojis, comments (depending on the "openness" of the specific page), etc. (Fig. 1). Facebook page owners can curate who can participate in terms of reading content and posting comments and reactions. Data generated on a social media platform like Facebook allows an analyst to "see" the volume of (i) consumption (through the number of "views") and (ii) production (through the number of reactions-in terms of "likes", and other emoticons/emojis, and top comments) every post receives; the nature of this consumption can be gauged primarily by the volume of reactions. Other members of Web 2.0 platforms can only be assumed to be in close symbiosis with one another, and post comments or click reactions for other potential readers (including the specific page host) in ways that supports such consumption. These media features shape the methodological framings of the data focused upon in this study.

\section{Methodological framings and data}

The significance of everyday mundane languaging in social practices, including the institutions in which people are embedded, have consequences for what is analysed as data. Here both the impact of new media and the need "to adopt a critical stance" for analysis is a key challenge (Flewitt et al. 2009: 44). Putting the analytical gaze on languaging constitutes renewed attempts to sidestep monological static understandings that mark essentialist, bounded notions of language and identity (see "Sociocultural perspectives and decoloniality as complementary analytical lenses" section). Since it is within the matrix of mundane interactions of everyday life that conventions are established (Berger 


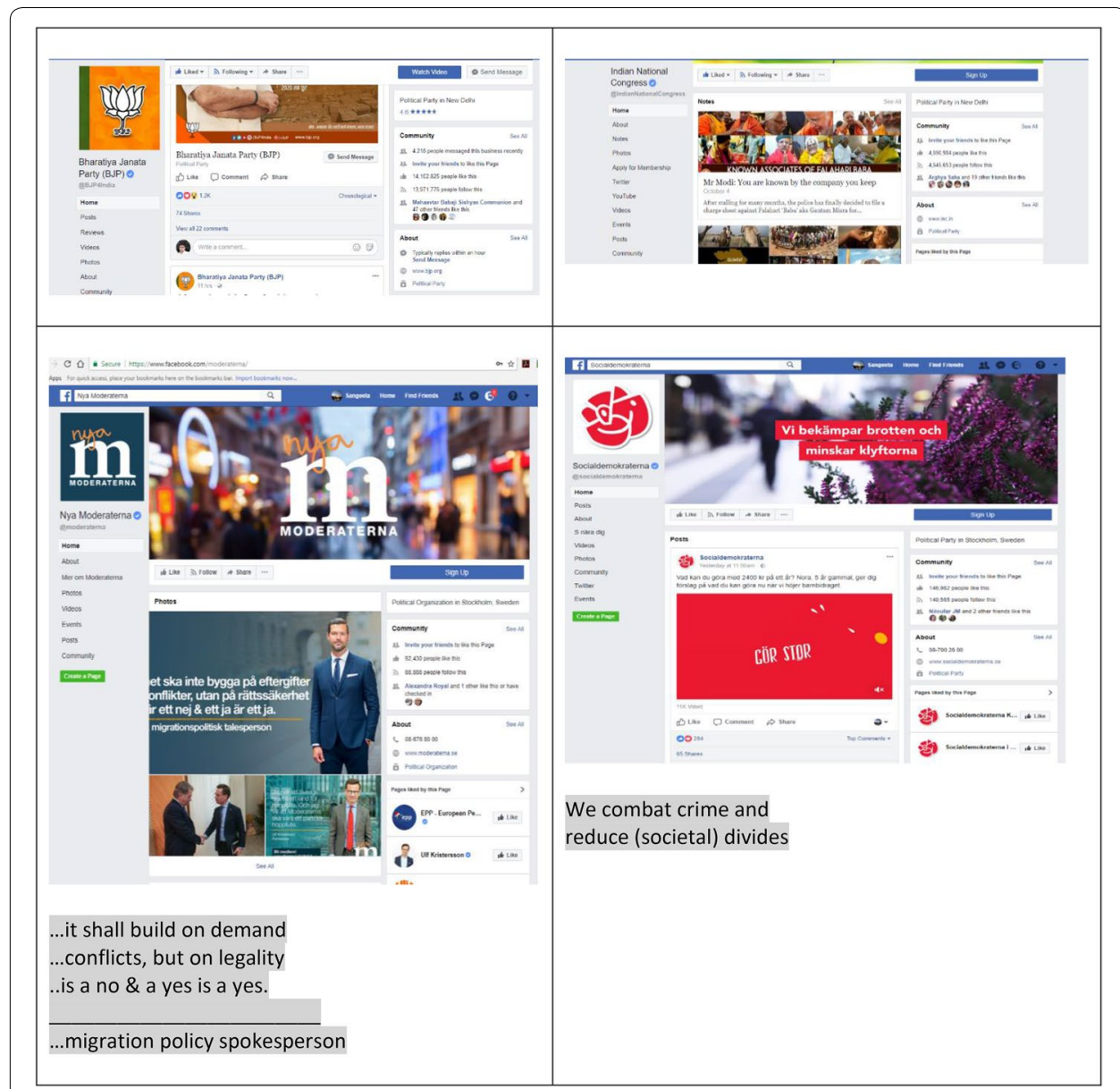

Fig. 1 First/opening pages of the four political parties: BJP, Congress, Moderaterna and Socialdemokraterna

and Luckmann 1966), there exists a need to address the complex nature of languaging itself.

The analytical-methodological framings drawn upon in this study build upon a unitof-analysis marked by a "Boundary-Turn" (Bagga-Gupta 2013) and other associated turns like the Colonial Turn and the Mobility Turn (Landri and Neuman 2014, Sheller and Urry 2006) in the literature on language and identity since the 1990s (see also BaggaGupta 2018; Clifford 1997; Hasnain et al. 2013; Scollan and Scollan 2004). Through analysis of empirical data, the case is made that a comparative framing where languaging is scrutinized from emic perspectives enables going beyond accounting of language as the sole property of communities or nation-states or individuals.

The data used here has been generated as part of the larger EL project (Everyday Life archives, ${ }^{4}$ ) at the CCD research group. ${ }^{5}$ Using an ethnographic design that focuses upon "natural" datasets, our objective has been to map the nature of contemporary languaging and political discourse in the mediascape Facebook. Analysis in ethnography, including

\footnotetext{
${ }^{4}$ Project Everyday Life Archives. http://www.ju.se/ccd/EL. Accessed 25 January 2018.

${ }^{5}$ Research Group Communication, Culture and Diversity, CCD. http://www.ju.se/ccd/. Accessed 25 January 2018.
} 
Table 1 Quantitative overview of the Indian and Swedish Facebook datasets of four political parties

\begin{tabular}{|c|c|c|c|c|c|c|c|c|c|c|c|c|c|c|c|c|}
\hline \multirow{2}{*}{$\begin{array}{l}\text { Political party/Time } \\
\text { period }\end{array}$} & \multicolumn{4}{|c|}{ Videos } & \multicolumn{4}{|c|}{ Infographics } & \multicolumn{4}{|c|}{ Live-videos } & \multicolumn{4}{|c|}{ Photographs } \\
\hline & B & $C$ & $\mathrm{~S}$ & $\bar{M}$ & B & $\mathrm{C}$ & $\mathrm{s}$ & $\bar{M}$ & B & $\mathrm{C}$ & $S$ & $\bar{M}$ & $\bar{B}$ & $C$ & $S$ & $\bar{M}$ \\
\hline 1-7 October & 9 & 11 & 0 & 8 & 21 & 18 & 4 & J & 9 & 0 & 0 & 3 & 19 & 14 & 4 & 4 \\
\hline 8-15 October & 5 & 10 & 1 & 13 & 25 & 24 & 4 & 2 & 6 & 1 & 0 & 6 & 22 & 28 & 3 & 2 \\
\hline 16-23 October & 12 & 10 & 3 & 2 & 20 & 23 & 5 & 2 & 7 & 0 & 0 & 0 & 17 & 5 & 3 & 2 \\
\hline 24-31 October & 7 & 9 & 1 & 2 & 19 & 11 & 7 & 6 & 8 & 1 & 0 & 3 & 20 & 12 & 9 & 4 \\
\hline 1-7 November & 16 & 3 & 2 & 1 & 23 & 16 & 1 & 4 & 6 & 4 & 0 & 0 & 21 & 51 & 9 & 3 \\
\hline 8-15 November & 14 & 5 & 4 & 5 & 25 & 20 & 5 & 6 & 4 & 3 & 0 & 1 & 23 & 68 & 3 & 4 \\
\hline Total & 63 & 48 & 11 & 31 & 133 & 112 & 26 & 25 & 40 & 9 & 0 & 13 & 122 & 179 & 31 & 19 \\
\hline Grand total B\&C+S\&M & \multicolumn{4}{|c|}{$111+42$} & \multicolumn{4}{|c|}{$245+51$} & \multicolumn{4}{|c|}{$49+13$} & \multicolumn{4}{|c|}{$301+50$} \\
\hline
\end{tabular}

B BJP, C Congress, S Socialdemokraterna, M Moderaterna

netnography, calls for making available accounts "of human social activity out of which cultural patterning can be discerned" (Wolcott 1999: 69). This means that while datasets have been systematically generated, we have mapped events in In and Sw in order to create local and cross-cultural understandings within which to situate the analysis and present accounts of cultural patterning. Thus, sociocultural framings of the nation-state contexts are taken into account in order to make sense of the social media data.

The data includes all posts across a six-week period-1/10 to 15/11 2017-on the official Facebook pages of four political parties. These include two dominant political parties in In: Bharatiya Janta Party (henceforth BJP) and the Indian National Congress (henceforth Congress), and Sweden: New Moderates (henceforth Moderaterna) and Social Democrats (henceforth Socialdemokraterna). All four party Facebook pages display maximum openness and access. This means that anyone with an internet connection can potentially access their pages. While the BJP is the largest party in the In parliament currently and has formed the government at the national level, the Congress is the largest opposition party. Socialdemokraterna is the largest party in the coalitionled government in Sw currently, and Moderaterna is the largest party in the opposition.

The dataset covers all posts and includes videos, live-videos, infographics and photographs posted on the official pages and comments and reactions by political party members and netizens. A first level of analysis included a day-by-day scrutiny of the entire data. This was categorized into number of videos, live-videos, infographics, photographs, likes, emoticons/emojis, etc. (Table 1) and included the creation of thematic patterns. A second level of analysis attempted to create an overarching picture of the patterns by identifying themes across every seven-eight-day period. Screenshots of salient themes were compiled for further analysis.

Table 1 illustrates the total posts uploaded by the four political parties across the sixweek period. The frequency of posts is higher in the In-dataset as compared to the Swdataset. Furthermore, the volume of posts differs across the parties: Socialdemokraterna have the fewest posts. While a total of 111 videos were posted by In political parties, the total number of videos posted in the Sw-dataset was only 40. This gap is also valid for infographics: In political parties posted 245 infographics, and Sw parties posted 51 infographics. In the data regarding live-videos, the total numbers posted by the BJP was 
over three times those observed in the Sw-dataset. A sharp contrast can also be noted with regards to photographs: the In parties posted six times the total uploaded by the $\mathrm{Sw}$ parties.

Facebook algorithms allow users to check the top comments for a given post. Using this system, the top 100 comments of some posts were chosen (based on the themes identified and the total reactions and comments they had received-for instance, as noted during the week-by-week analysis) for further systematic analysis. Here the focus was on the emerging themes and the nature of languaging. The next section presents our ethnographically framed analysis.

\section{Discourse and mediascapes}

Three clusters of themes that overlap in different ways emerged in the systematic analysis of the datasets. These are discussed and illustrated in this section.

\section{Media features, convergence and participation spaces}

The specific features of Facebook enable different types of affordances in terms of the type of discourse and participation that is possible. Four issues related to these features contribute to the first theme that has emerged.

\section{Common Facebook features}

Facebook verifies pages belonging to well-known institutions/organizations or individuals. Facebook page "owners" can present a cover photograph and a profile picture on their "main" page. Credentials of the person or the institution/organization that "owns" the pages are available here (unless the owner does not add such information or decides to keep this information closed for non-"friends"). These include contact details and the "about" section on the homepage presents biographical data about the individual or institution/organization. Most institutions/organizations also have a "sign up" option here. Three of the four political parties-Congress, Moderaterna and Socialdemokraterna-offer netizens the "sign up" feature on their homepages (Fig. 1). The Congress and Socialdemokraterna have an "apply for membership" link on their pages, while the BJP and Moderaterna don't. Facebook pages also allow internet users to post links on a political parties' official website. Homepages in the datasets included hyperlinks to photographs, videos (including live-videos) and other messages posted by the party.

\section{Convergence and re-cycling}

Many messages or items that are uploaded on the political parties' pages have been picked up from elsewhere. For example, short TV-footage from other media channels by political parties on Facebook (Fig. 2). This constitutes an instance of convergence or recycling in mediascapes. Such convergence allows political parties to actively publicize a political leader's TV appearance or other messages across different media. This can also be seen in the use of hashtags, which was originally invented for the microblogging website Twitter in 2007 and which entered the realm of Facebook in $2013 .{ }^{6}$ Online users cre-

${ }^{6}$ CNN Hashtags http://edition.cnn.com/2013/06/12/tech/social-media/facebook-hashtags/index.html. Accessed 15 January 2018. 


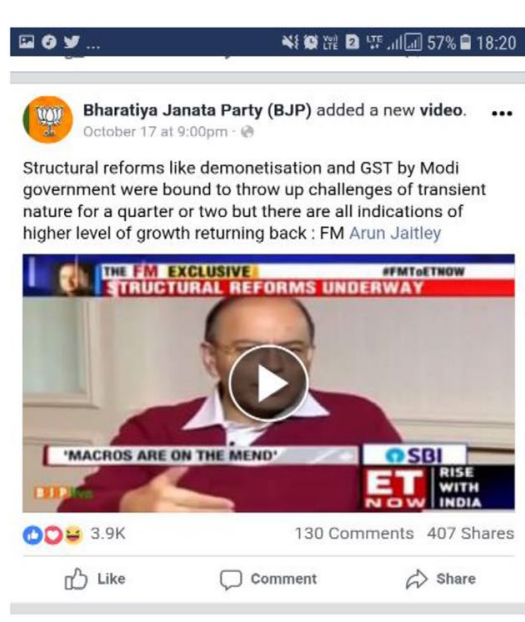

Indian National Congress added a new video: BJP ... \& RSS Thoughts on Women

The B.JP and RSS are not known for being proponents of gender equality

ake a look at how their key figures have disrespected women.

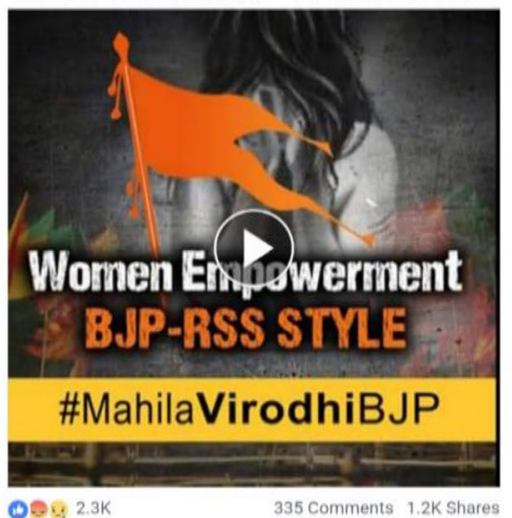

$\cos 2.3 \mathrm{~K}$

3.2K Shares

U. Uke

$\square$ comment

ఏ) share

\#AntiWomenBJP

Fig. 2 Re-cycling of media content by political parties BJP (17/10 2017) and Congress (16/10 2017) on their Facebook pages

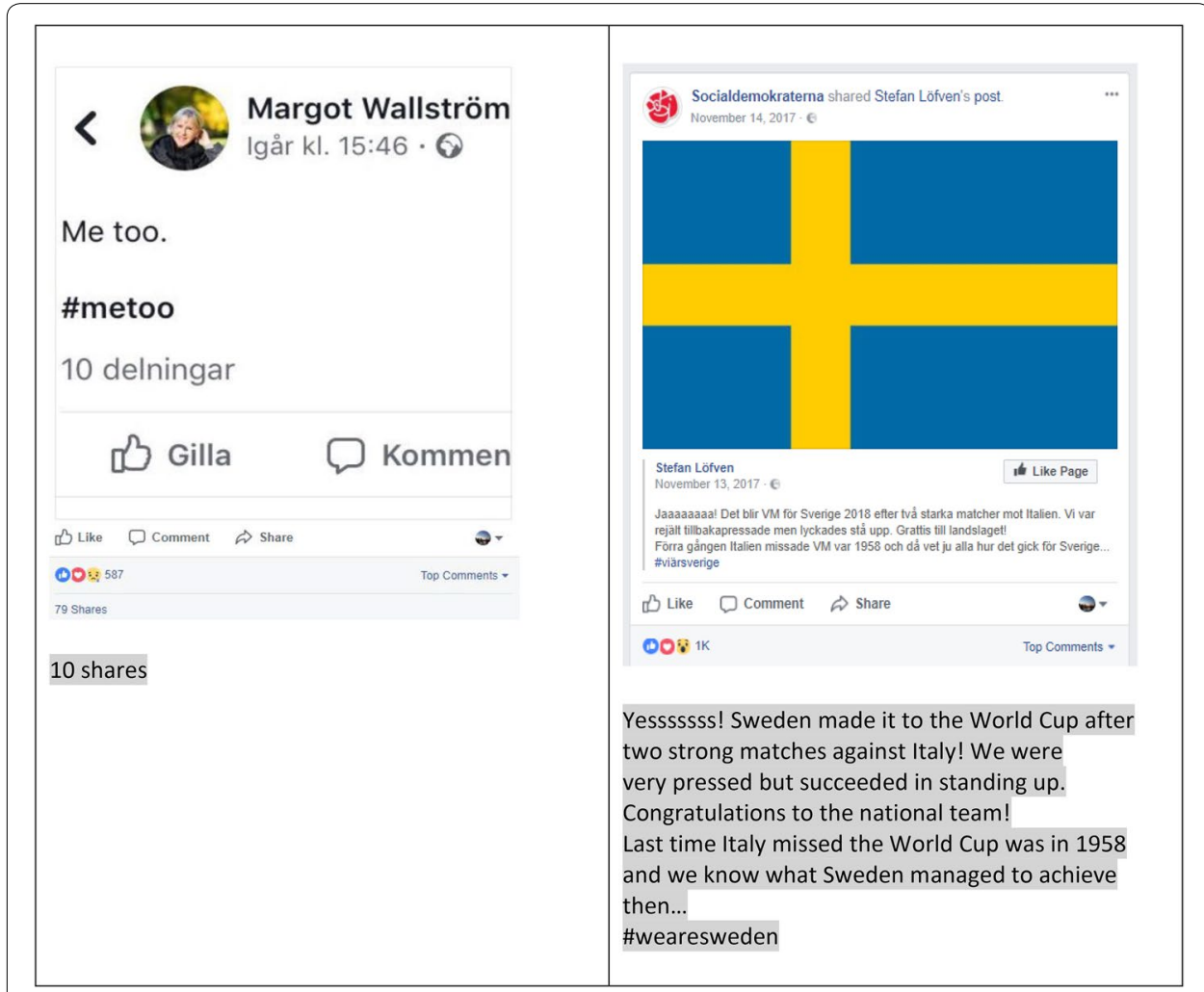

Fig. 3 Re-cycling of politicians' personal posts on political parties' Facebook pages (3/11/2017; 14/11 2017) 


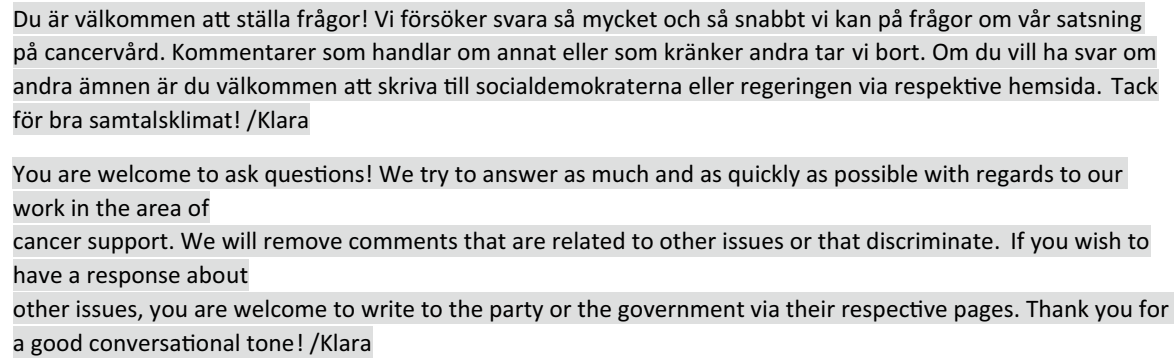

Fig. 4 Party representatives' participation in the commentary flow on Facebook pages

ate hashtags to discuss specific events and relevant issues (Figs. 2, 3). In comparison to the Sw-dataset, the In-dataset displays generous usage of hashtags (see "Languaging features in social media" section).

Figure 2 displays a screengrab of a video (BJP page) where the In Finance Minister Mr. Arun Jaitley is speaking to a TV-channel regarding structural reforms like GST (Goods and Services Tax; implemented in July 2017) and the structural overhaul of the entire monetary system called "demonetization" (implemented in November $2016^{7}$ ). A second screengrab in Fig. 2 (Congress page) illustrates the use of footage from TV-media as well as a hashtag highlighting the RSS's (the parent organization of BJP) alleged anti-woman mindset.

\section{Participants and participation patterns}

While Sw political leaders' posts on their individual Facebook pages were at times recycled on their party pages (Fig. 3), this was never the case in the In-dataset. Additionally, there were no instances of any politicians directly interacting with the netizens in the commentary sections of the posts. This is interesting given that two politicians who appear frequently in the In-dataset-the prime-minister Mr. Narendra Modi and the BJP party head Mr. Amit Shah-are active users of Facebook (and other mediascapes).

Figure 3 displays two posts-that of the Sw foreign minister Ms. Margot Wallström and prime-minister Mr. Stefan Löfven from their individual Facebook pages-that are picked up and presented in the official pages of their party, the Socialdemokraterna. In both cases the message has a clear relevance to prominent events in society: the first is Wallström's participation in the \#metoo movement that strongly impacted institutions/ organizations and public arenas, and the second is Sweden's qualifying for the 2018 football World Cup, after they beat strong favorites Italy. Both these re-cycled posts also display hashtags-something that is not common in the Sw-dataset: \#metoo and \#viärsverige (we are Sweden). In addition to the participation of political leaders in discourses in mediaspaces, Fig. 3 highlights an important theme related to identity-positions (see "Identity-positionings in political social media" section) i.e. discourse where politicians and parties display an allegiance with the citizens and their concerns. This is one way in which new media constitutes an affinity space where assemblages are formed.

\footnotetext{
7 Firstpost.com Demonetisation http://www.firstpost.com/business/demonetisation-anniversary-a-year-later-hereswhat-prime-minister-narendra-modi-had-said-on-8-november-2016-4198753.html. Accessed 1 January 2018.
} 


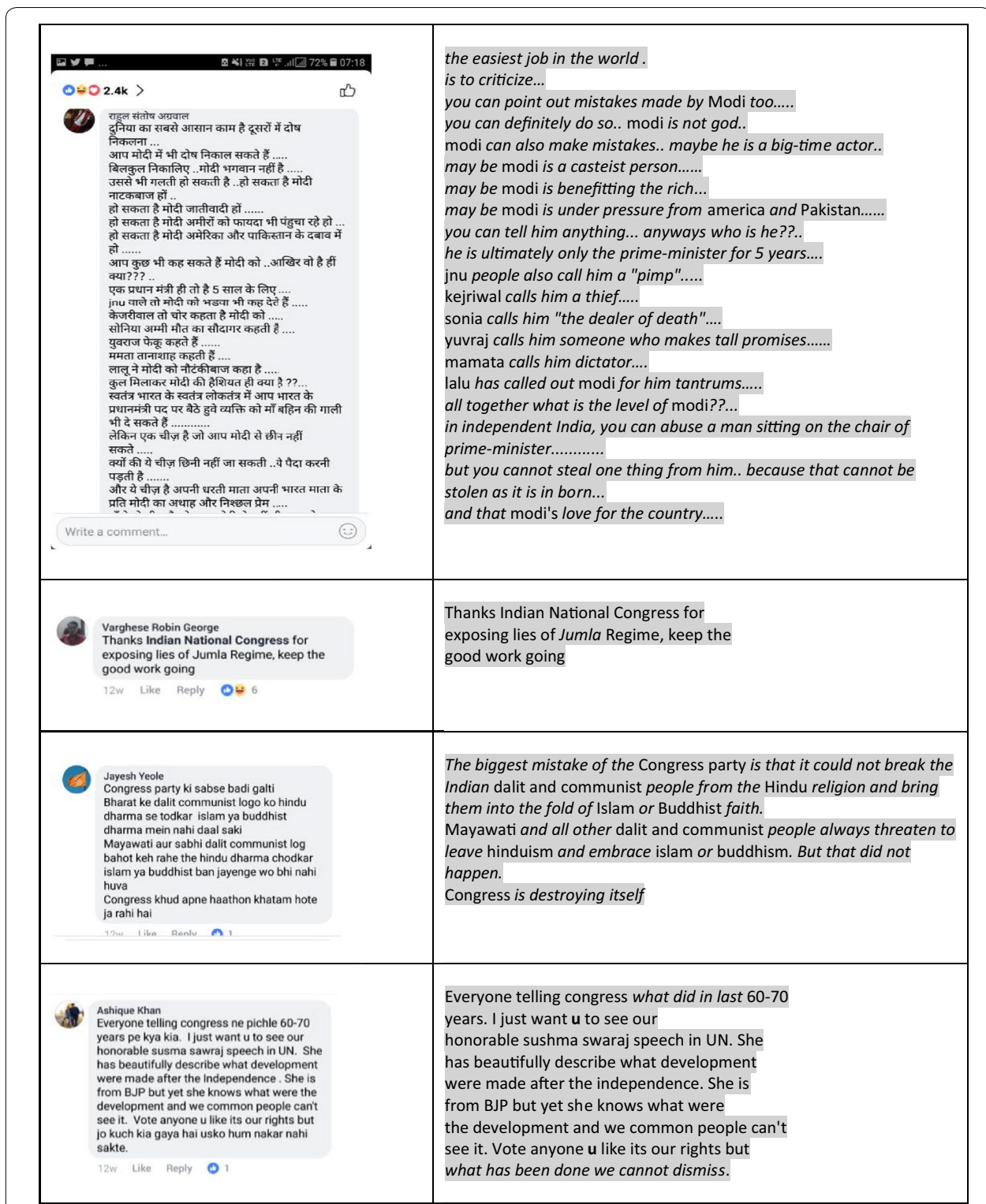

Fig. 5 Citizens participation on political parties' mediascapes (28/10 2017; 8/11 2017; 11/10 2017; 8/11 2017)

Party representatives from Socialdemokraterna also regularly comment on their party Facebook page (Fig. 4), responding to comments by netizens in the comments section. They often address the person who has put up a post with a "Hi" and sign off using their first names. The party specifically urges participation on their webpages in a civilized manner and asks comments to be issue-specific with a good tone.

Netizens participation on party Facebook pages in terms of uploaded comments and reactions (emoticons/emojis, shares) opens up the political dialoguing arena for (potentially) everyone. A number of themes emerge in the analysis of this type of engagement. While the Sw-dataset consists of posts and comments that are only presented in Swedish (including digital languaging; see Moderaterna and Socialdemokraterna screengrabs and "Languaging features in social media" section), the In-dataset displays the use of at least 
three language-varieties (English, Hindi, Gujarati) and two scripts (Latin, Devanagari), including digital languaging (Fig. 5; see BJP and Congress screengrabs and "Languaging features in social media" section). Access to the comments is dependent on participants (or any reader's) knowledge of these scripts and the ways in which they are "chained" in languaging (see "Languaging features in social media" section).

The long Hindi comment in Fig. 5 in the Devanagari script criticizes the opposition parties and detractors in In for criticizing the prime-minister. The next two screengrabs in Fig. 5 illustrate the use of both English and Hindi in the Latin script. While the regular font illustrates English, italized text marks Hindi/Gujarati in our translations. However, one can ask whether the English marked text, primarily nouns like Congress, Dalit community, Islam, Buddhist, Hindu religion, or Mayawati (a politician's name) belongs only to English or to both the language-varieties in use here. The term "party" is similarly fuzzy in that it can be understood as both Hindi and English. Similarly, issues can be raised for proper-nouns like Modi, Kejriwal, Sonia, Yuvraj (a moniker for Mr. Rahul Gandhi), Mamata and Lalu (names of senior politicians in different parties), and names of two countries-America and Pakistan; the salient issue here is that it cannot be taken for granted that these terms are part of only one or the other language-variety. The commentators' use of the Latin script, albeit in small case letters, to present the name of a well-known university is interesting here: "jnu" (Jawaharlal Nehru University). This represents digital languaging (see "Languaging features in social media" section).

A commentator uses the word "Jumla", a negative term that points to the sorry state of affairs in the country. While this lexical item is not new in Hindi, its present connotation with respect to the government makes it a neologism in In political discourse. Furthermore, composite words that build upon English and Hindi morphology and syntax are used by the authors, pointing to Web 2.0 participants knowledge of such usage. We see two examples of such languaging in Fig. 5: "feku" (originating from the Hindi term "phekna", to throw) and "pappu" (a dumb person)-terms used here to describe the In prime-minister and the Congress party chief. The last screengrab in Fig. 5 illustrates another feature common in digital languaging (see also "Languaging features in social media" section): the use of the short form " $u$ " for you, small-case letters for politicians' names (sushma swaraj).

Netizen comments are very diverse across the six-week period that the datasets cover. Many of these are related to issues of identity-positions (Fig. 6; see "Identity-positionings in political social media" section). Participants in the In-dataset often focused on corruption and related terminology "corrupted", "corrupt", "scam", "brashtachar" (Hindi: corruption). This focus on corruption as a socio-economic problem stood out from the rest of the themes in the In-dataset. A number of these comments relate to the demonetization drive that was initiated by the BJP government in November 2016. Another striking theme that emerges in the In-dataset commentary is what can be called "leaderdebasing" or "hero-worshipping", including nationalism (see "Identity-positionings in political social media" section). Referring to the leader of the Congress party, Mr. Rahul Gandhi (son of the former leader Ms. Sonia Gandhi and son and grandson of the late prime-ministers Mr. Rajiv Gandhi and Mrs. Indira Gandhi respectively), the comment is negatively framed and ridicules the political leaders' actions (regarding visiting religious places). The final participant comment presented in Fig. 6 not only marks the leaders 
Jeet 'pj' Nagda

IIP is up. Exports are up. Inflation is stable and low, food inflation is at lowest, Current account Deficiet is down. Sensex and Nifty are up.

Only corruption is down so that pinches the congress !

10w Like Reply (t) 2

View 1 previous reply

Jeet 'pj' Nagda GDP decrease was a temporary...

19. Muralidhar Rajaram

"India is benefited from Modi's

demonetisation and has also given perfect reply to the terrorists $\mathrm{n}$ CORRUPTED CPM n

Write a comment

Raaj Aradhya

A moron who never vistied Temples in $40 y e a r s \&$ also said those who go to temples molest women is visiting Temples all of a sudden $\hat{\theta} \hat{\theta} \hat{\theta}$

You can Copy Modi, but can't become one..

9w Edited Like Reply (OO $\approx 0$

Bhupal MI We support modiji bjp government the great leader and dynamic leader modiji we proud to have such a great leader jaihind

Like - Reply - 12w

We support Modiji bjp government the great leader and dynamic leader Modiji we proud to have such a great leader Hail India

Fig. 6 Some themes in citizen participants' comments (8/11 2017; 13/11 2017; 17/10 2017)

name by adding the respectful "ji" (modiji), but hails the prime-minister as a great leader. Here the commentator signs off with a patriotic "jaihind" (Hindi: hail India; a salutation to the nation-state).

Comments to the party posts in the Sw-dataset are often either negative comments directed towards the opposition or direct questions aimed at specific posts (Moderaterna, 15/11) or a positive post (Moderaterna, 13/11); these often elicit a response by a party representative (Fig. 4) or other like-minded netizens. The first participant comment on the Socialdemokraterna posts are often by a party representative who invariably recommends participants to keep their comments focused, requests for good etiquette and presents further links, photographs to support the main post (6/11; Fig. 4).

A mis-match between the party posts and comments that participants write below them are common. Figure 7 illustrates this issue: while the caption clearly criticizes the Gujarat state-government for ignoring the health of children in the state, the comment below it is concerned with issues in another state (Himachal Pradesh) in northern-India. 


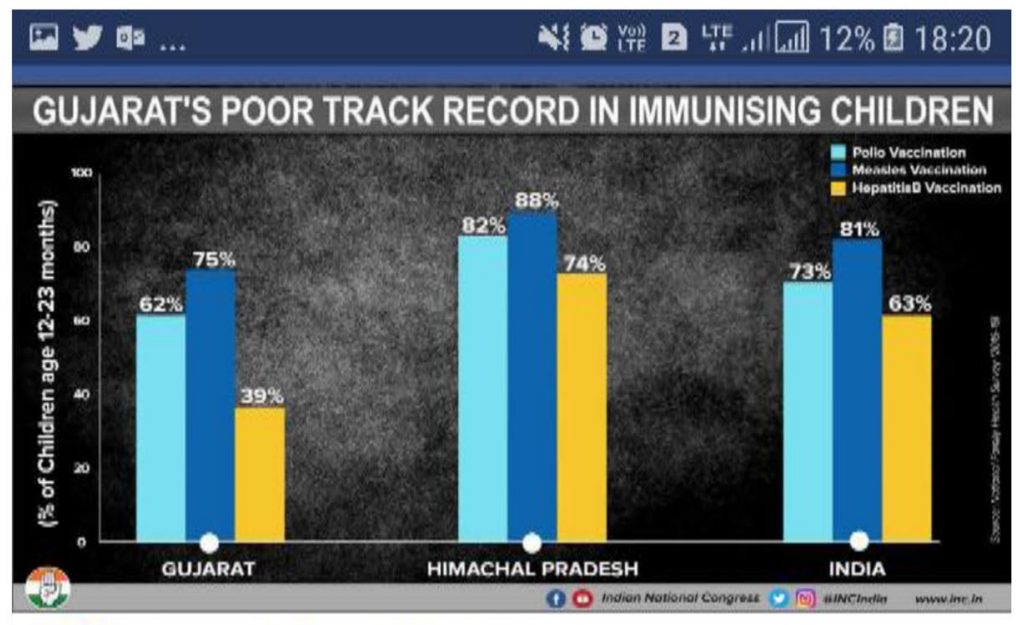

Indian National Congress

Statistics show how much care the Gujarat government really extends towards the health and immunity of its children.

Timeline Photos $\cdot$ Oot $30 \cdot \theta$

Vlew Full Size ' More options

0 Like $\square$ comment $\Rightarrow$ share

$\theta=1 \mathrm{~K}$

156 Shares

Write a comment...

$\odot$

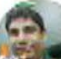

Shailendra Mishra

Is ka matalab himanchal pradesh me congess dobara aane wali hai . Lekin aisi agar na hua to jhuthi Congress kya karegi besharmi ki had ho gayee.

This means that congress will return to power in himachal pradesh. However, if this does not happen, what will the lying Congress do there is no limits to shamelessness.

Fig. 7 Mis-match between message and captioning of post and participant comments (30/10 2017) 


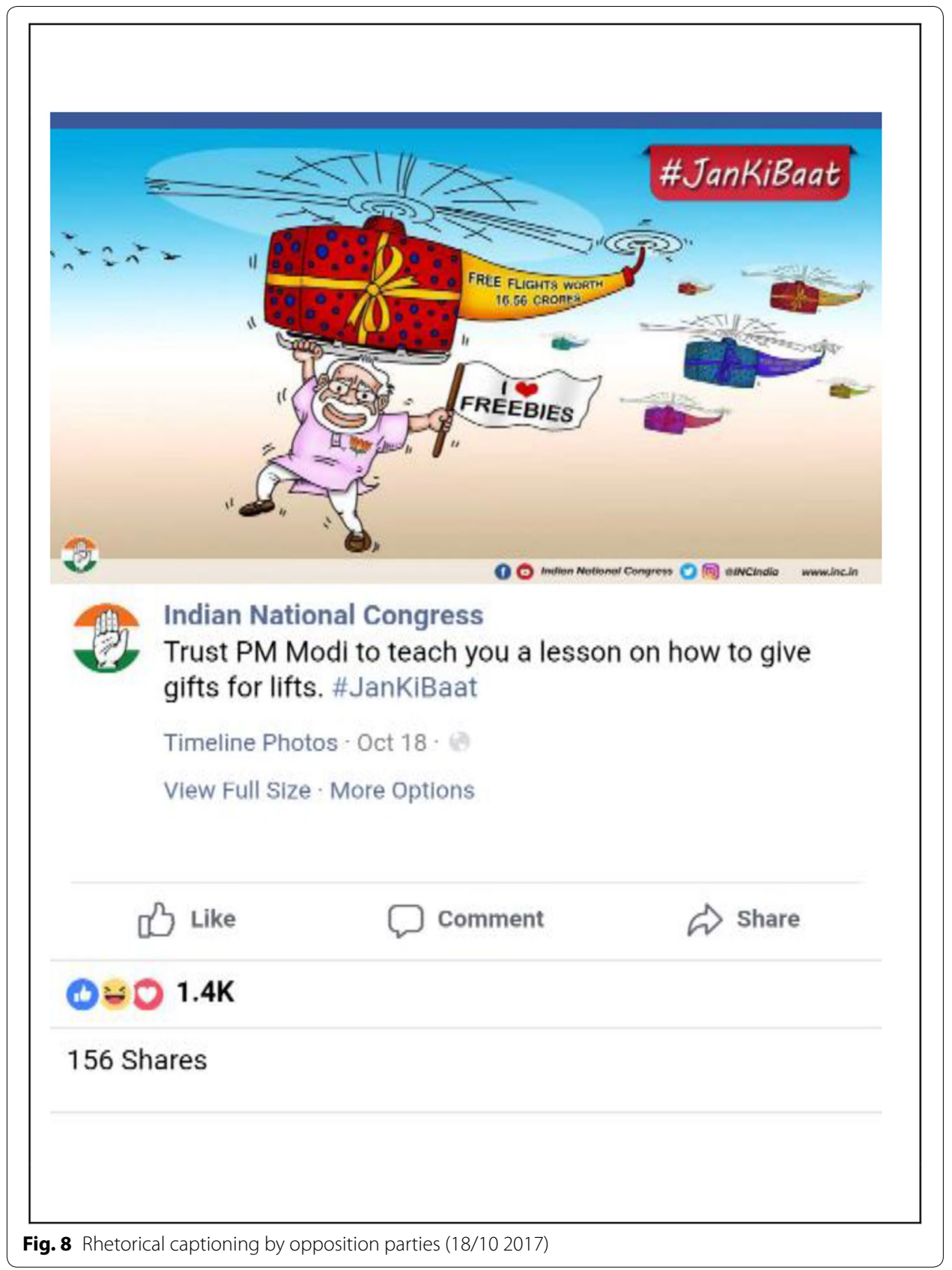

The participant, using abusive language, chides the Congress. The explicit message presented by Socialdemokraterna party representatives (Fig. 4) asking citizens to only write comments relevant to the post and present other issues in other sites also illustrates this issue of mismatch. This highlights a possible loss of opportunities for dialoguing between citizens and politicians.

\section{Captions and slogans}

Some type of a caption or slogan accompanies every Facebook post in the dataset. Some of these are simple; for instance, use of rhetorics or puns are limited in BJP captions. In 


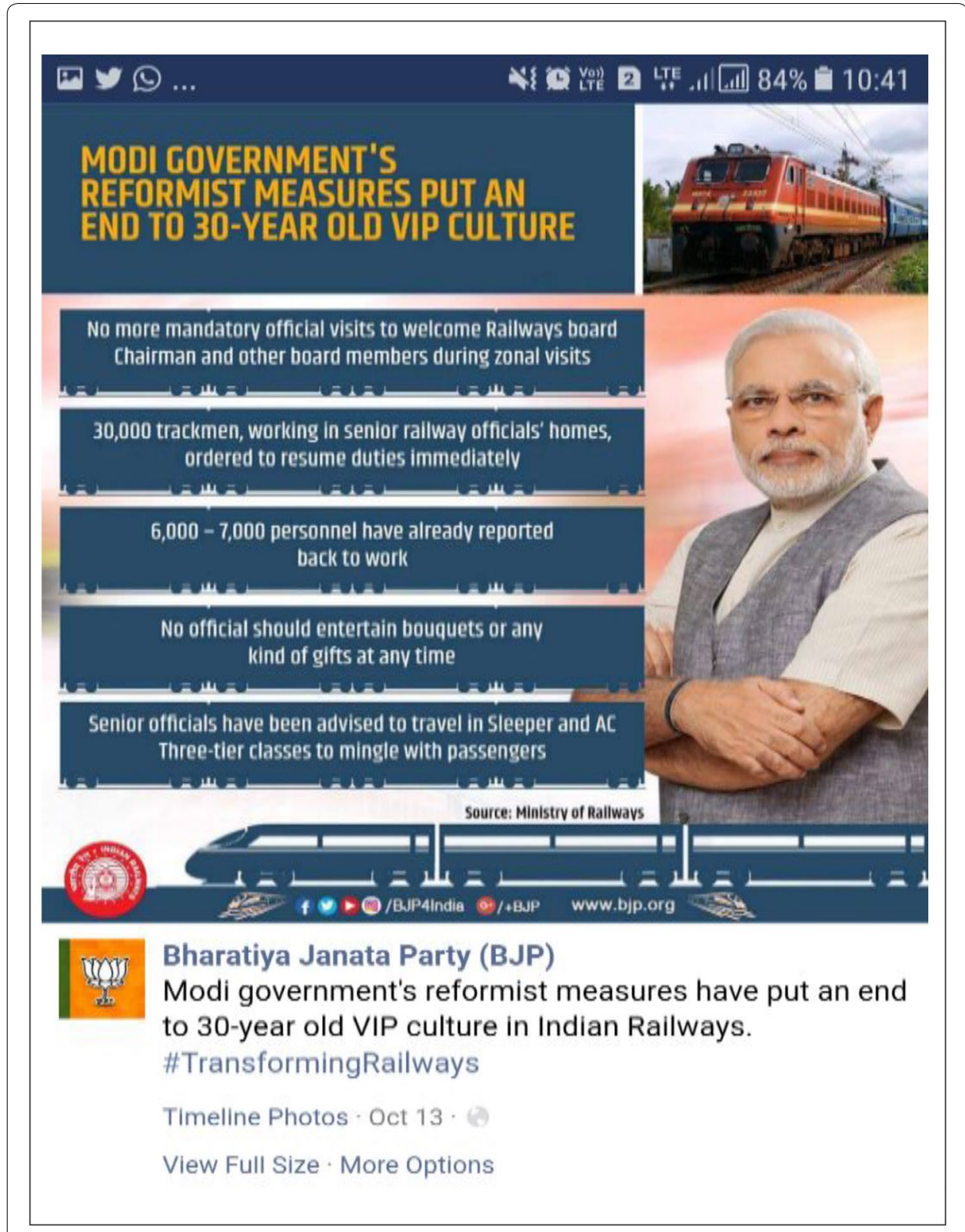

Fig. 9 Recycling of messages in political party posts (13/10 2017)

contrast, Congress pages regularly incorporate wordplay, rhetorics and puns: targeting prime-minister Mr. Narendra Modi for allegedly favoring corporate houses, Fig. 8 uses humor to criticize the governments' policies. The last three words in the caption, "Trust PM Modi to teach you a lesson on how to give gifts for lifts" rhyme and taunt the primeminister, whose caricature holds a helicopter in one hand and a banner, in the other, that reads "I love freebies". The hashtag “\#JanKiBaat” (Hindi: People's thoughts) furthermore, plays with the prime-minister's popular monthly show on All India Radio, titled "Man Ki Baat" (Hindi: Private thoughts).

While Moderaterna and Socialdemokraterna posts implicitly call attention to one another's lack of achievement during their governance, they uncommonly target one 


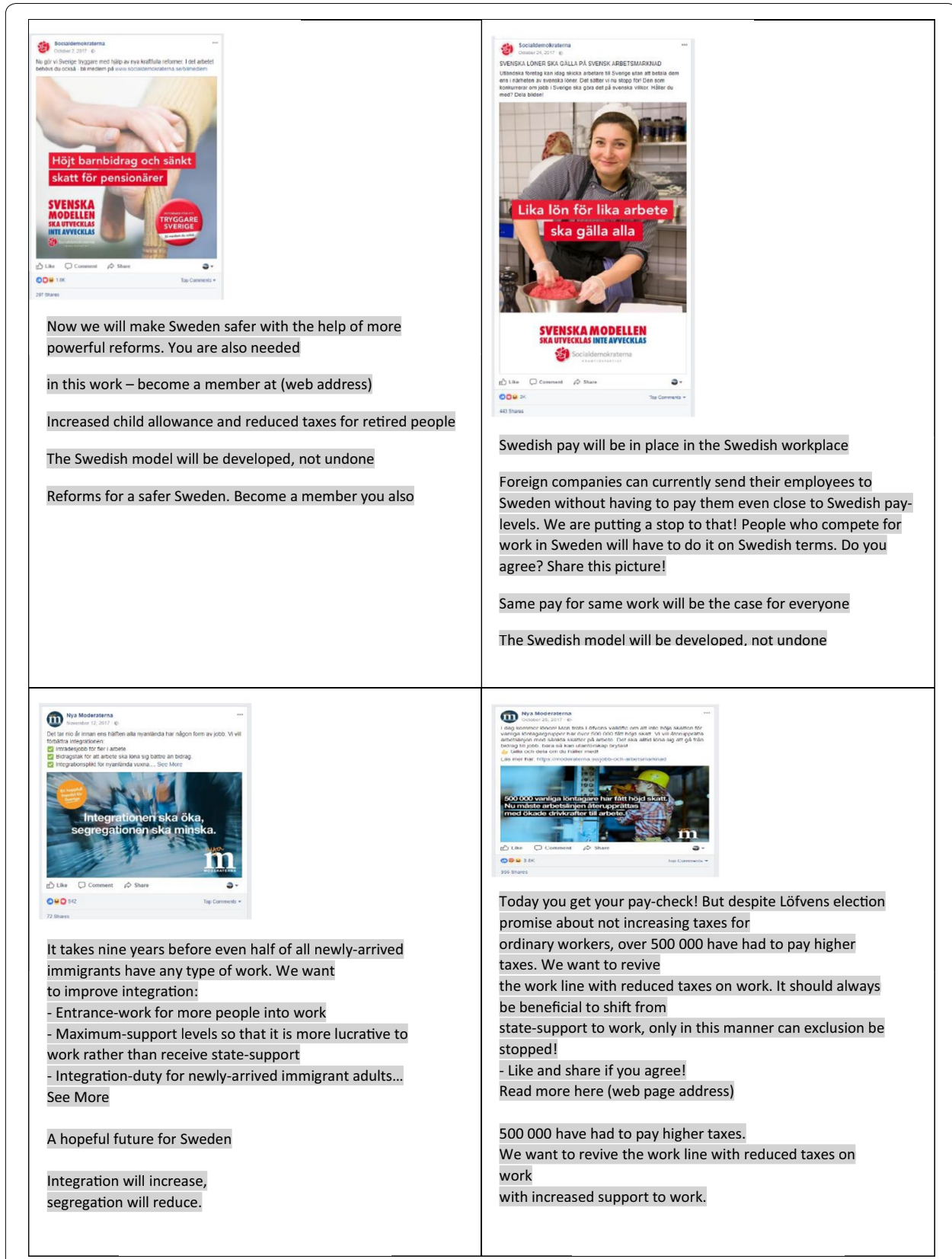

Fig. 10 Slogans in Swedish political social mediascapes (a 2/10 2017; 24/10 2017; b 12/11 2017; 25/11 2017)

another's leaders in such a manner. Posts of the Socialdemokraterna were simpler as compared to posts by Moderaterna. Recycling of captions and slogans with other messages in the posts is a common feature in the dataset (Fig. 9).

Many posts or infographics/pictures sections that are re-cycled display elements of slogans. Slogans constitute a common feature of the Swedish party posts. Slogans calling on citizens to join as members are common in the Sw-party posts: "Bli medlem du också" (Swedish: Become a member you too). Figure 10a presents two common types of pictures used with slogans. In the first, three slogans are presented together with a 
faceless embodiment where two hands can be seen (the younger hand is caringly placed above an elderly hand holding a walking stick):

i. "Höjt barnbidrag och sänkt skatt för pensionärer" (Swedish: Increased child allowance and reduced taxes for retired people) is centered;

ii. "SVENSKA MODELLEN SKA UTVECKLAS INTE AVVECKLAS" (Swedish: The Swedish model will be developed, not undone) in the left lower corner; and

iii. "REFORMER FÖR ETT TRYGGARE SVERIGE. Bli medlem du också" (Swedish: Reforms for a safer Sweden. Become a member you too) on a round button in the right lower corner.

In addition to the messages and pictures, color schemes reinforce political party identity-positions. The messages associated with Socialdemokraterna in Fig. 10a are in red while the color associated with Moderaterna (blue) is used to present the negative message here. Figure 10b from the Moderaterna pages are similarly presented in tones of blue, the party color. The BJP and Congress posts are also color-coded with saffron and a white lotus, including a green vertical ribbon on the left (BJP) and the orangewhite-green horizontal bars (representing the In national flag) with a white upright hand (Congress).

The second type of picture associated with slogans, presents a leading politician or an unknown individual (Fig. 10a). Two women, one staring at the viewer and one whose head is covered in a shawl (and is almost not visible) are presented with texts regarding equality of pay in the workforce. Unequal pay for men and women on the one hand, and for foreign investors on the other, are targeted in the slogans here. In Fig. 10b, a woman worker is presented as a backdrop to the information regarding the need to get people off state-support and back into the labor-market. An important feature of infographics where slogans are presented is the re-cycling of messages. This re-cycling appears in all four examples presented in Fig. 10a, b, reinforcing political messages and ideologies.

\section{Identity-positionings in political social media}

Many aspects that are relevant to the theme of identity-positions have already been touched upon in "Media features, convergence and participation spaces" section. The second theme (of three) that emerge in our analysis relates to identity-positions more specifically. Three issues contribute to this theme that in itself overlaps with the other two themes that have emerged in the analysis. Aligning to scholarship that goes beyond traditional understandings that regard identity as "a stable structure located primarily in the individual psyche or in fixed social categories" (Bucholtz and Hall 2005: 586), our point of departure is that identity relates to dimensions of a person, group or a phenomenon that is stable in some sense over time (Bagga-Gupta et al. 2017; Gleason 1983; Wetherell 2010; Wetherell and Mohanty 2010). Allegiance with the nation-state (or states in the In sub-continent), religions, party ideologies, or other communally constituted fractions, or key politicians are relevant dimensions of identity-positionings in the discourse that plays out on mediascapes. 


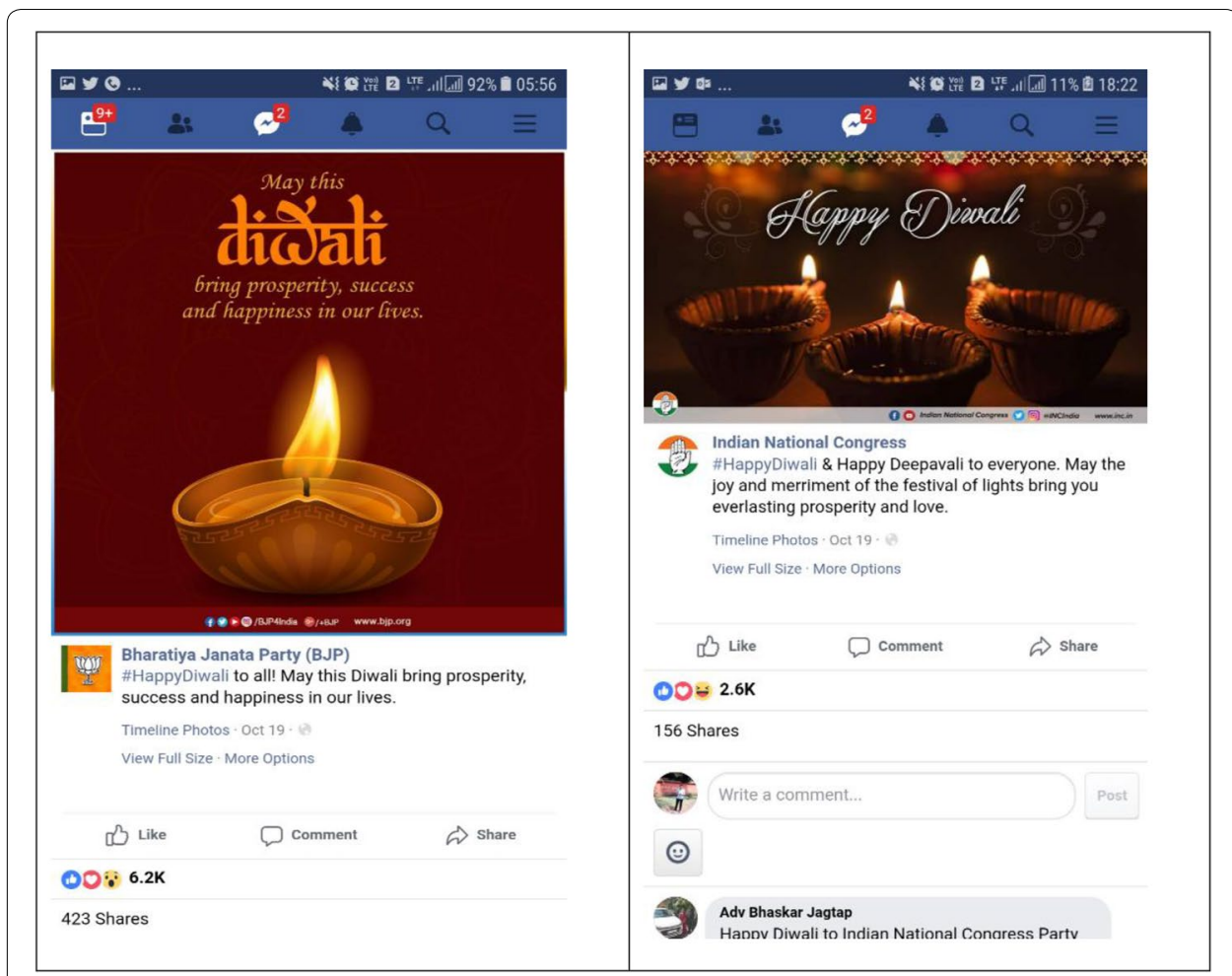

Fig. 11 Political party greetings on festivals (19/10 2017)

\section{Religion and secularism}

Citizens in both In and $\mathrm{Sw}$ have the right to freedom of religion. While the In-constitution explicitly frames the nation-state as a secular country, Sw is officially a kingdom whose constitution builds upon a parliamentary democracy. While the state and the church in Sw went separate ways in 2000, Christianity remains a part of the public realm in that-in comparison-expressions of other religions that are practiced by the citizenship are marginal in official or medial discourses. While an amendment to the In-constitution incorporated the word "secular" over four decades ago (in 1976), interpretation of secularism in In has been a matter of debate. However, what is relevant for the present analysis is that all religions are part of the public realm and four world religions acknowledge the geopolitical spaces of In as their birth site.

Hindu festivals dominated the data generation months of October-November, and the In-dataset shows that both parties greeted citizens on different occasions (Fig. 11). For instance, both parties greet netizens on Diwali that is celebrated across the sub-continent. The imagery in these posts showcases lighted diyas (lamps), since Diwali is the "festival of lights". The lexical item "Diwali" is presented in the Latin script with the horizontal line of the Devanagari script across the top. In addition, the In-dataset includes photographs of the two main leaders of BJP and Congress visiting temples (Fig. 12). Such actions by the politicians and the prominence they receive on social media platforms highlight efforts to align the party-political discourse towards different groups in society. In other words, an act of identity-politics, the greetings, the temple-visits and the presentation of such events, are important dimensions of political discourse. For instance, 


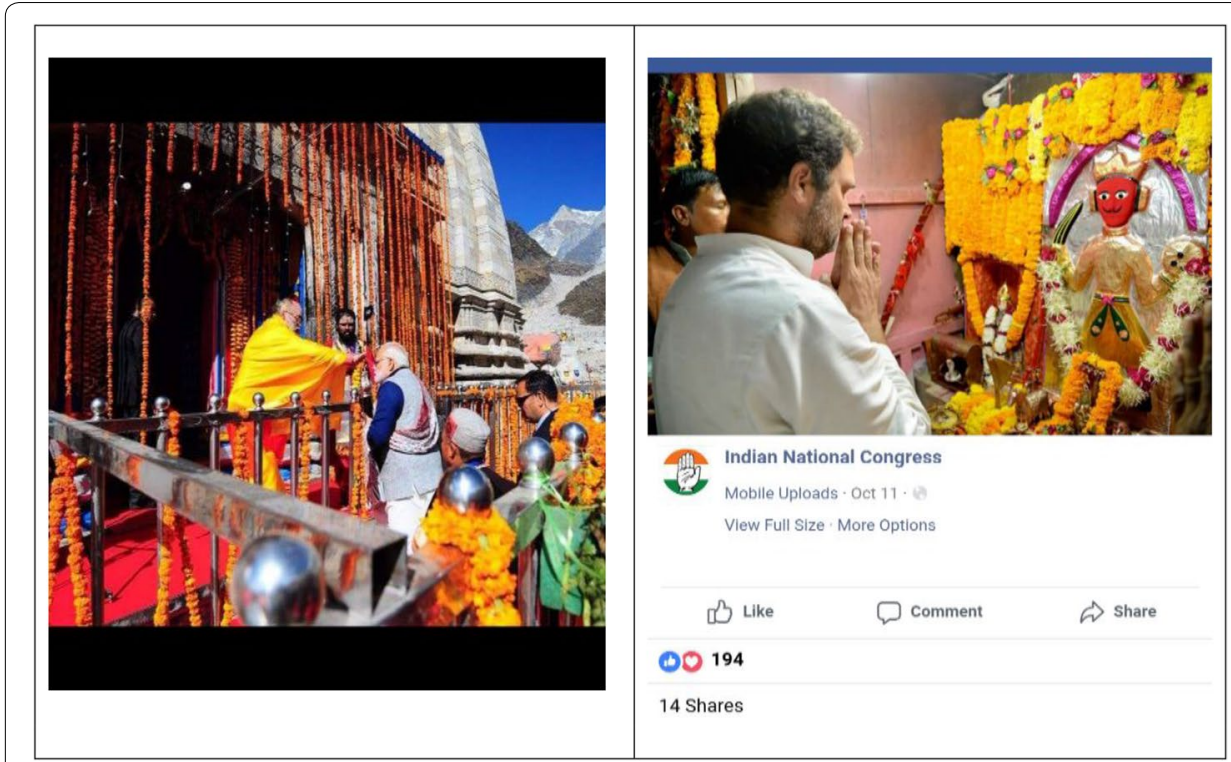

Fig. 12 Political party leaders visiting religious sites (19/10 2017; 11/10 2017)

Mr. Rahul Gandhi's visit to several temples in Gujarat in October 2017 coincided with his campaign in the state (for the December 2017 elections). These temple visits have been discussed in terms of a possible bid to woo Hindu voters to the Congress. ${ }^{8}$

The saffron color associated with Hinduism is also the color of BJP's party emblem. In addition to religious festivities, giving recognition to significant dates and anniversaries connected to a political party also creates identity-positionings for party leaders and the party itself. Figure 13 is a re-cycled post from the Sw prime-ministers page where he congratulates the youth wing of the Socialdemokraterna on their 100th anniversary. The post includes a YouTube video especially created to commemorate the occasion for the party congress in 2017. This highlights the convergence (see "Media features, convergence and participation spaces" section) and re-enforcement of the party's history, ideologies and identity-positionings.

\section{Patriotism and nationalism}

Patriotism and allegiance expressed towards the nation-state, regional-states or communal groupings, and their symbols and important dates are prominent identity-markers in the datasets (see above). Figure 14 highlights identity-positions in terms of sub-nationalism related to the Gujarat state-elections (held in December 2017). Here both BJP and Congress use hashtags, videos and infographics that explicitly express such an allegiance. While the BJP's post presents its core message in the Devanagari script, its hashtags are presented in English in the Latin script: \#ProudToBeGujarati and \#ProudToBeIndian. In contrast, while the Congress post presents its core message in English in the Latin script, its hashtags are presented in Hindi albeit in the Latin script: \#GarvSeGujarati (Hindi:

\footnotetext{
${ }^{8}$ Indian Express Gujarat elections http://indianexpress.com/elections/gujarat-assembly-elections-2017/gujarat-elections-2017-rahul-gandhis-devotion-to-temple-politics-catches-bjp-off-guard-4976225/. Accessed 15 January 2018.
} 
Socialdemokraterna shared Stefan Löfven's post.

October $28,2017-\mathbf{C}$

Stefan Löfven

October $28,2017-6$

Grattis SSU pã 100-ẩrsdagen!

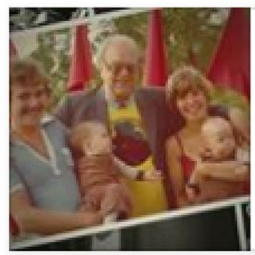

100 år av SSU

SSU:s jubileumsbildspel som togs fram till kongressen 2017. Bilderna kommer frản Arbetarrörelsen arkiv och..

YOUTUBE.COM

\section{(3) Like \\ Comment \\ Share}

(b) $=670$

Top Comments .

Congratulations SSU on your $100^{\text {th }}$ anniversary!

Fig. 13 Identification and allegiance to own party (28/10 2017)

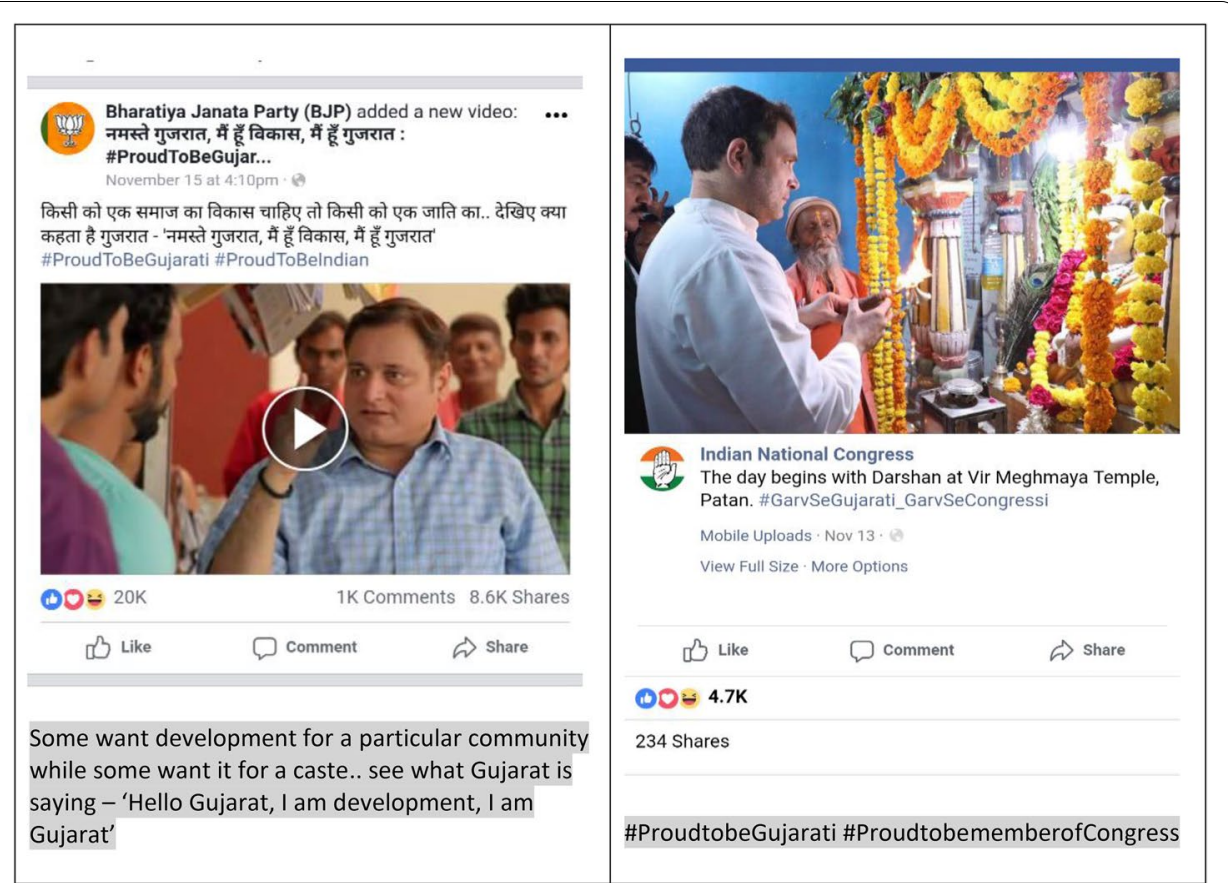

Fig. 14 Identification and allegiance to different groups: "Proud to be Gujarati", "Garv Se Gujarati", "Proud to be Indian", "Garv Se Congressi" (15/11 2017; 13/11 2017) 
proud to be from the state of Gujarat) and \#GarvSeCongressi (Hindi: proud to be member of Congress). While both parties highlight ethnic-linguistic pride vis-à-vis Gujarat as a significant dimension of their political agendas, the BJP highlights an In national identity while the Congress highlights membership in their party as a significant dimension of a voters' identity. This can be understood in terms of the fact that the primeminister and BJP leader are from this state, while the Congress party and its leader (who is presented in the photograph) need to make their identification to citizens in this state explicit.

Similar issues can be seen in Fig. 3 ("Media features, convergence and participation spaces" section) where the Socialdemokraterna party page shared prime-minister Stefan Löfven's post. The national flag covering the entire post can be regarded as an unusual photograph given the concerted efforts by the government and Socialdemokraterna to distance themselves from nationalism. However, in the context of sports, expressing exhilaration at the nation-states qualification for the 2018 football World Cup legitimizes such a post. In contrast, the Congress party's symbol, an upright-hand superimposed on the tricolors of the national flag, has a clear nationalistic connotation.

\section{Cult of personality}

The dataset shows that all four parties forefront their leaders (see "Media features, convergence and participation spaces" section). However, there appears to be a stronger personality-centric approach in the discourse of the In-dataset. This is visible through the uploaded photographs, hashtags, live-videos and videos. The prime-minister is omnipresent in the In-dataset (as can be gleamed from the figures presented so far; see also Rao 2017). While the first screengrab in Fig. 15 is text-centric and presents the headlines of different international print-media, his picture is part of the infographic. The title of the infographic is also the main message of the post: "World bodies stick to their endorsement of PM Modi's reform measures". In addition to the omnipresence of the prime-minister, this can be understood as an instance of "local-chaining" (see "Languaging features in social media" section) where reinforcement of key messages and a strong identification with the prime-minister is salient (even in data where his picture is not present).

While the BJP uses their leaders' surname in their posts, the Congress uses their leaders' first name (second screengrab, Fig. 15): the hashtag \#NavsarjanwithRahul also highlights a personality-driven approach to electioneering in Gujarat. Navsarjan, a Gujarati lexical item presented in the Latin script, means revival or new beginnings. While the Sw-dataset also has examples of a personality-driven political discourse, either full names or no names of the politicians are presented. The third screengrab (Fig. 15) is a collage of three photographs where the prime-minister is showcased interacting with both citizens and the police-force during his much-publicized tour of the country (primarily in the marginalized suburbs of larger cities and rural areas). Identification with the citizenship and members of the security forces is an important theme that emerges in the $\mathrm{Sw}$-dataset. This maps onto what is being perceived as heightened issues of national security threats and lawlessness together with the need for political parties to engage with the concerns of the common person. The last two screengrabs illustrate such concerns through the imagery of strong and committed political leaders. The 


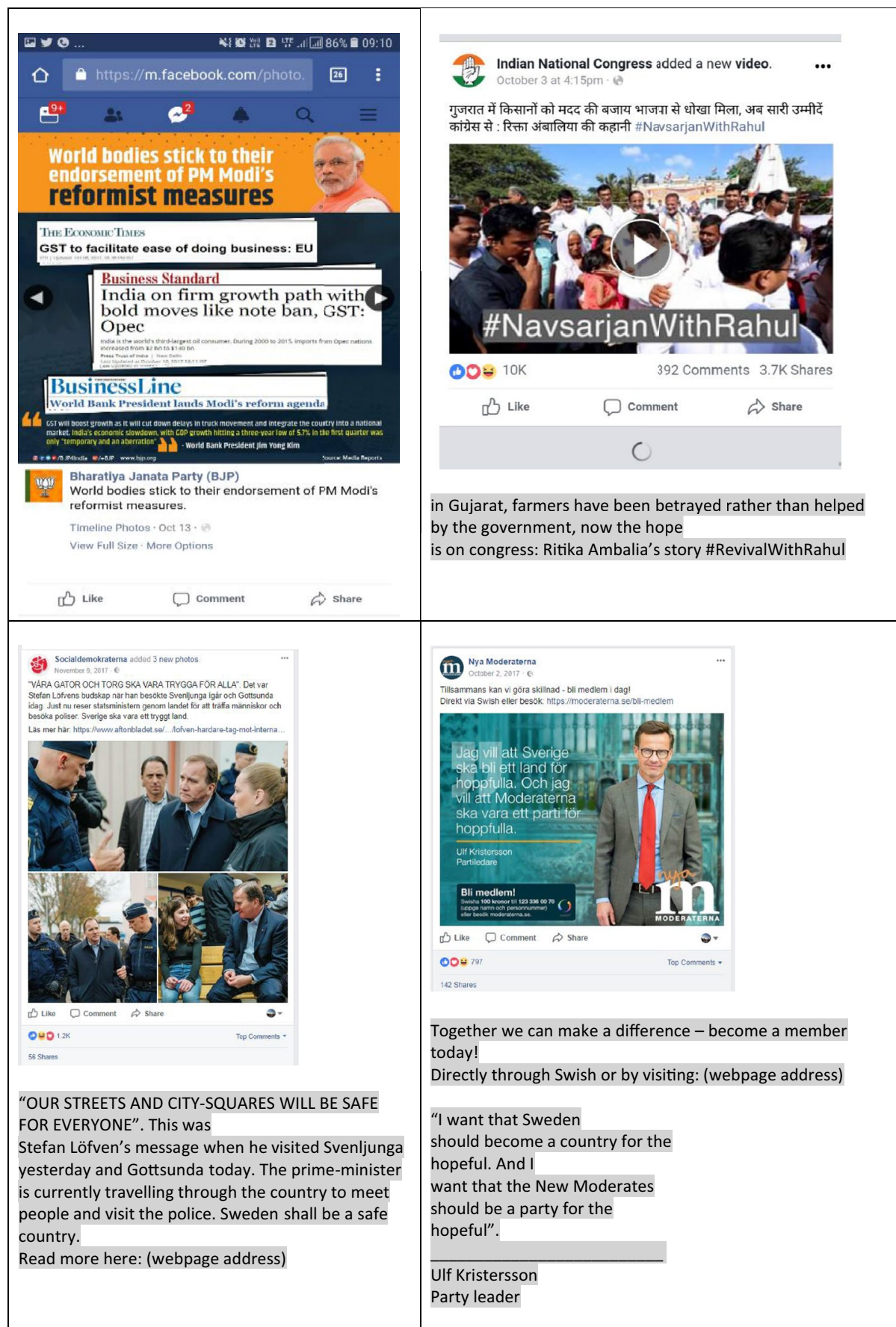

Fig. 15 Political leaders-personality cult (13/11 2017; 3/10 2017; 9/11 2017; 2/10 2017)

repeated presence of the party leader of the Moderaterna in the Sw-dataset can also be understood by the fact that Mr. Ulf Kristersson replaced Ms. Anna Kinnberg Batra who resigned from her post at the end of September 2017. 


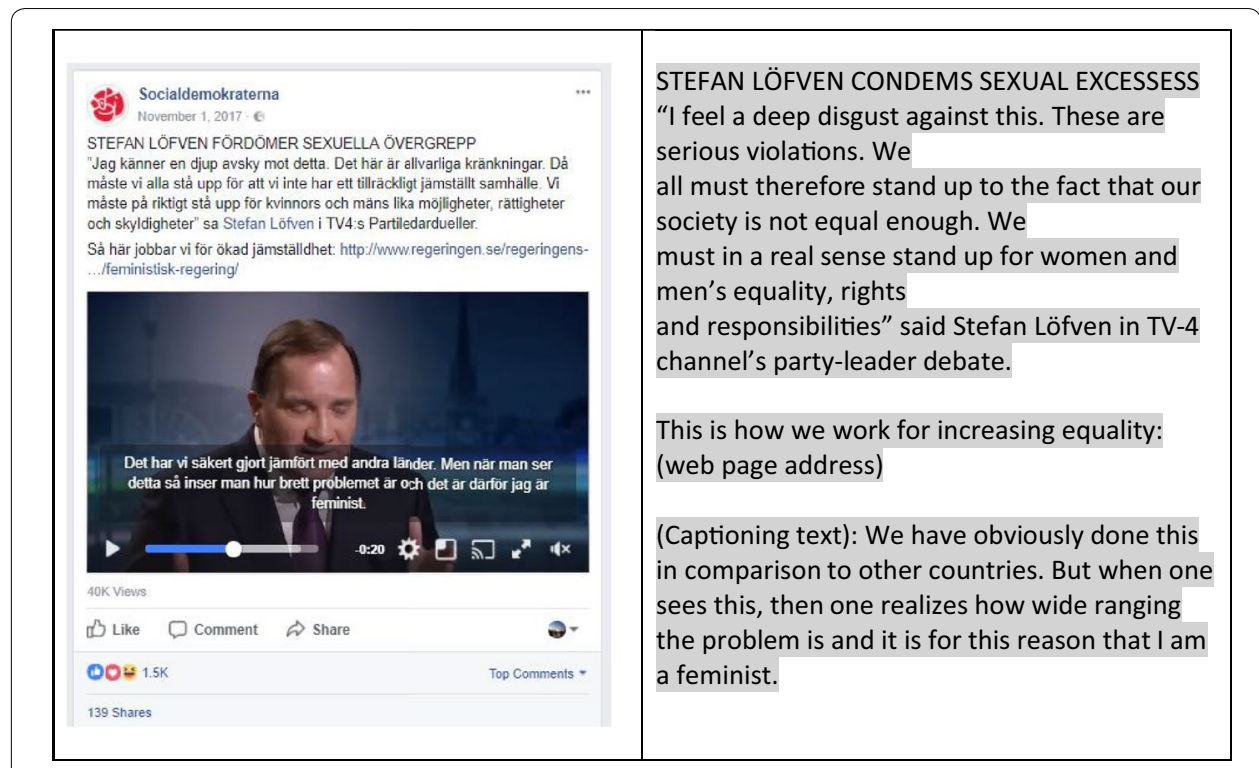

Fig. 16 Subtitled video screengrab from the Sw-dataset (1/11 2017)

\section{Languaging features in social media}

Issues of relevance to the final theme that has emerged in the analysis, i.e. language, have been both implicitly and explicitly touched upon in "Media features, convergence and participation spaces" and "Identity-positionings in political social media" sections. Three issues that contribute to this theme are presented here.

\section{Content-chaining and local-chaining}

As has been illustrated above, the very fabric of Web 2.0 mediascapes like Facebook opens up for both the re-cycling of content from other media-types wherein partymembers posts (from their individual Facebook pages) or TV-broadcasts or newspaper texts, etc. are presented (see for instance, Figs. 2, 3, 7, 9, 12, 14). Such re-cycling of content constitutes "content-chaining" of digital media, including texts from across the spectrum of other virtual platforms (Twitter, Instagram, YouTube, etc.; Fig. 14) and media (TV, newspapers, blogs, etc.; Figs. 2, 3, 7, 9, 12, 14). Content-chaining is marked by the modality pluralism of languaging in digital spaces (see also Gynne and BaggaGupta 2015; Messina Dahlberg 2015). Content-chaining often has the goal of presenting a convergence of a specific message (this includes, but is not restricted to, party slogans; Figs. 10, 14); it also highlights some news or event (Fig. 2). Party symbols and colors are also important dimensions of content-chaining.

Another form of chaining that has been identified (see "Media features, convergence and participation spaces" and "Identity-positionings in political social media" sections) as a dimension of the nature of languaging in the political party mediascapes relates to the language-varieties/modalities and other semiotic resources in the datasets. As highlighted earlier, while the In-dataset display the deployment of at least three languagevarieties (English, Hindi, Gujarati), including at least two scripts (Latin, Devanagri), the Sw-dataset displays the use of only one language-variety (Swedish) in the Latin script. 
Furthermore, in the In-dataset, words and phrases presented in Hindi or English are transliterated into the script that is conventionally deployed by the other language-variety (see Figs. 2, 5, 6, 7, 14). Such languaging blurs the boundaries between language-varieties. Figures 8, 9, 10, 11, 13, 14, 15, 16 highlight the chained use of oral (video), written (infographics, comments), pictorial, embodied communication, etc. Such "local-chaining"-irrespective of whether one or more language-varieties/modalities are in use-has been identified in the In- and Sw-datasets. Local-chaining represents a routine discursive-technological order where more than one language-variety/modality, resource and tools are used by the participants.

\section{Subtitling and access}

While subtitling is part of local-chaining, it merits special attention given that nonsubtitled videos from other media (TV, YouTube) are subtitled prior to presentation in the political party posts. The volume of uploaded videos, recycled-videos and livevideos in the datasets varies (Table 1). Quantitatively there are fewer live-videos in the $\mathrm{Sw}$-dataset as compared to the In-dataset. One political party in each of the two nationstates-BJP and Moderaterna-have quantitatively more live-videos than their counterparts (Table 1). While all the uploaded and recycled-videos (for instance, from TV-news channels) in the Sw-dataset are subtitled in Swedish (Fig. 16), none of the In ones are subtitled. The Sw-dataset is interlingually subtitled. Figure 16 illustrates a screengrab of a video-clip that presents key statements made by the prime-minister during a leading TV-channels party-leader debate where issues of sexual harassment and discrimination were discussed. This theme became a key topic across the media following the \#metoo movement in Sw.

Here is it interesting to note that the Sw TV-news broadcasts are not automatically interlingually subtitled during their live-broadcasts (all non-Swedish oral language is, however, intralingually subtitled). This means that both the political parties get these videos interlingually subtitled before they are uploaded on their pages. In contrast, none of the live-streamed videos in the datasets are subtitled. Subtitling in Swedish makes oral Swedish language available for participants who, for different reasons, cannot access spoken Swedish language. This suggests that issues of accessibility are attended to in the Sw political parties mediaspaces. However, it can be argued that the monolingual nature of the languaging in the Sw-dataset curtails issues of access for citizens who use language-varieties other than Swedish. In contrast, the Hindi-English (and Gujarati) languaging in the oral and written modalities in the In-dataset, it can be argued, is more inclusive for citizens.

\section{Digital languaging}

As the analysis in "Media features, convergence and participation spaces" and "Identitypositionings in political social media" sections has richly illustrated, digital conventions are an important dimension of the languaging in current political discourse (Figs. 2, 3, 5, $6,7,13,14)$. A unique feature of digital languaging is the use of emojis and emoticons to convey sentiments. These have become popular among netizens across the globe and its usage is more popular in the In-dataset as compared to the Sw-dataset. This means that in addition to experiences with different conventional language-varieties and an internet 
connection, participants need to know how to make sense of digital language conventions in order to be able to participate in social practices where symbols like "\#" or webpage addresses constitute dimensions of the languaging.

Hashtags can (potentially) draw attention to a message in a minimalistic manner. TV broadcasts in In are noted for using hashtags to either criticize or praise a person or an issue. Some hashtags in our datasets clearly reveal a specific point of view/ideology that a post attempts to promote. However, an understanding of events across time in the national contexts (for both netizens and us, the analysts) are a pre-requisite for meaning-making of the content of digital languaging. This means that while the political party pages are (potentially) accessible to anyone anywhere, such access is contingent upon familiarity with language-varieties/modalities deployed on the page, contextual knowledge as well as conventions of digital languaging. For instance, the hashtag \#vadfanfårjag (Swedish: what the hell do I get) itself refers to the Socialdemokraterna message (6/11) that everyone needs to contribute with taxes in order to get access to free education, health-care and other services. The Congress hashtag \#JavabDegaHimachal (Hindi: the state of Himachal Pradesh will respond) in the infographic, accompanying a video (7/10), points to the upcoming state elections $(9 / 11)$. The Congress ruled the state and the hashtag points to a response by the citizens that could bring them back to power in the state. A BJP hashtag that accompanied a video (6/11), \#ModiDhumal4Vikas (Hindi/English/digital: Modi and Dhumal for Development) brings to the forefront another dimension of digital languaging in global-South settings like In: while the term "vikas" can be attributed to the language-variety Hindi, it is also part of Asian Englishes. Furthermore, being proper nouns, the two politicians' names-prime-minister Mr. Narendra Modi and Mr. P.K. Dhumal-cannot be said to belong to only Hindi, English or for that matter Swedish. Furthermore, the number " 4 ", is part of standard digital languaging and denotes "for" (and also "four").

The idea that one language is bounded and completely distinct from other languagevarieties, builds upon political ideology. As highlighted in the "Introduction" section, recent global-North scholarship explicitly problematizes such monolingual and monocentric biases (Gramling 2016). However, these discussions tend to occur among European (American and Australian) scholarly networks, that do not include the rest of the world. These global-North discussions have proposed neologisms that are in themselves problematic, not least since key points of departure related to their emergence include recent waves of migration, including digitalization in global-North spaces themselves (Bagga-Gupta 2017a, b, 2018; Bagga-Gupta and Dahlberg 2018). A comparative viewing of digital datasets of political parties from across GSN settings therefore is significant, and potentially allows for critically understanding how language plays out in public mediascapes.

\section{Discussion and reflections on ways-of-being-with-words across the global-South/North}

"Currently, there are probably as many foetal theories of Internet language behavior around as there are linguists; The Internet is the largest area of language development we have seen in our lifetimes" (Crystal 2011: 148; 149) 
In addition to contributing from analysis of empirically framed scholarship to illuminating the area of new mediascapes, what do the findings of this study offer in terms of mundane political languaging or the "ways-with-words" (Heath 1983) and the concomitant identity-positions or "ways-of-being" (Bagga-Gupta 2014) across GSN settings? Furthermore, in addition to making relevant a multi-theoretical and multi-disciplinary stance, what new types of issues have been made visible when empirical datasets across GSN settings are focused upon within the same analytical framings? Going beyond decolonial framings where global-North hegemonies are commonly articulated, does an engagement with decoloniality (in particular in an empirical study) contribute in specific ways to current concerns regarding communication and diversity in the global-North? These are the types of issues that this study has attempted to explore and can contribute towards. These are discussed broadly in this final section.

Emerging in the early 1990s, the internet has succeeded in shrinking the world metaphorically and literally. It allows scholars from different disciplinary hues to reflect upon the powerful, highly problematic ideas related to bounded, "imagined communities" (Andersson 1994), including demarcated nation-states. A focus upon datasets made up of political parties' Facebook pages requires the creation of empirical materials that emerge from the local contexts of two different nation-states. However, such mediascapes, unlike the constructed boundaries that demarcate one nation-state from another, are not hermeneutically sealed spaces; they are part of the larger medial landscapes, including societal contexts. The internet allows anyone with a technological device and a connection, including a desire to connect with anyone else with similar connectivity, to connect. Here language has been and continues to be an issue-particularly in terms of access to the "multilingual internet" (Crystal 2011: 78-91). Reports on global usagepatterns ("Media-types across spaces. Some perspectives on India and Sweden" section) highlight that the internet-usage picture is not static, and the new media situation across GSN settings cannot be simplified to an issue of haves-have-nots.

Savransky's (2017) call for cultivating a decolonial imagination means that scholarship needs to focus upon the here and now in all spaces, including re-viewing datasets that can empirically contrast the here and now across GSN contexts. The findings in this empirically framed study highlight the multilayered communication that makes-up discourses that circulate in the Facebook pages of political parties across GSN contexts. The specific media features of the social networking site Facebook, that is reported to be immensely popular in both nation-states, support complex processes of convergence where materials from other media are curated and presented. In addition to the political parties who host the Facebook pages, active participants in these pages include party representatives and netizens. Political leaders' participation in these "affinity spaces" (Gee 2005) takes place in different ways. For instance, (i) when leaders' posts from their individual Facebook pages are re-cycled on the parties' pages; (ii) when a special post is created center-staging them in some special role or with a special message; or (iii) when a leader is positioned in lieu of the party symbol and ideology. This "cult of personality" pattern is stronger in the In-dataset, and more-so in the BJP materials, but is present in the datasets from both nation-states.

Patterns of participation that emerge in the analyses raise issues concerned with unreached/reachable potentials for democratic dialoguing between parties, politicians and 
citizens. In addition to a mismatch between comments by netizens and the contents/ themes of uploaded party posts, the "interaction order" (Goffman 1983) at this scale can be understood in terms of the following:

- an initiation of a topic when a post is uploaded (I),

- a comment by a citizen $(C)$, and

- a response by a party representative (R) or

- a comment-response by another citizen on the same thread as the first comment $(\mathrm{C}-\mathrm{R})$.

Such ICR/C-R sequences are common in the analyzed datasets. They do not constitute dimensions of rich/in-depth dialogues. The latter would involve discussions that enable the emergence of newer understandings or positions. These interactional patterns have some semblance to the classical IRE (initiation-response-evaluation) interaction order typical of classroom instruction (Mehan 1979). Other interactional features on Facebook-the "thumbs-up" likes, emoticons/emojis, shares, links to other websites, etc.too do not enhance dialoguing between politicians and citizens in any clear-cut manner. It is perhaps the case that new media features do not support such dialoguing. Thus, mediascapes offer parties and politicians a new platform to advertise curated positions. This includes displaying allegiances with citizens and their interests and concerns and downplaying the opposition. This orientation is a dimension of identity-politics: politicians align their activities and discourse towards different communities, including personality-driven approaches and different ways of identifying with the citizenship; they engage with citizens and accentuate differences between ideologies. Such orientations project strong and committed political leaders. "When political parties and candidates directly connect with potential voters through social media, and give them the option of 'like' the posts and 'comment' on messages and pictures in an interactive manner, it creates an element of personalization" (Saleem and Stephan 2016: 91). Since a personalization element is limited in the datasets, the findings raise issues concerning the promise of democratic potentials of contemporary mediascapes. Thus, while Web 2.0 platforms hold promise of being democratic platforms (Narayan and Narayanan 2016; Schroeder 2016), analysis at the micro-scale presents a gloomy picture.

Other features vis-à-vis identity-positions are related to the issue of secularism. While secularism is understood in global-North spaces in terms of the separation of religion from the state (which would suggest that secularism is officially a new situation in $\mathrm{Sw}$ ), in the context of In, secularism can be more clearly understood in terms of "Sarva Dharma Samabhava" (Sanskrit: equality of all faiths). This is recognized as being part of Hindu philosophy and its essence has been pushed by scholars and leaders like Vivekananda, Ramakrishna and Mahatma Gandhi; Sarva Dharma Samabhava embodies "the equality of the destination of the path's followed by all religions (although the path's themselves may be different)". ${ }^{9}$ Without claiming that such an ethos can automatically ${ }^{9}$ Wikipedia Sarva Dharma Sama Bhava. https://en.wikipedia.org/wiki/Sarva_Dharma_Sama_Bhava. Accessed 20
December 2017. 
solve issues related to societal tensions, it holds promise for current challenges faced by global-North settings like Sw and Europe.

Despite popular understandings of what is understood as secular, the analyses suggest that while there exists a recognized pluralism in In, a hegemonic mono-religious norm exists in Sw. Given that the Swedish state separated from the church only in 2000 also calls attention to why (in comparison to the In-dataset) no religious symbols or slogans have been identified in the Sw-dataset. Could their very absence in political party discourses highlight a disconnect between the multiethnic citizenship in Sw and the primarily mono-ethnic political elite? For instance, othering in public discourses in Sw has, in the twnty-first century, become marked through implicitly linking Islam with terrorism/extremism. In this light, religious plurality that marks public spaces in In, where all religions are openly marked and celebrated becomes interesting (this is not to deny the challenges inherent for individuals and groups who profess allegiance to different religions in "normally diverse" settings like In). The point that is interesting for present purposes is that differences in identity-positionings between the two nation-states highlights the importance of contributions from the global-South towards invigorating understandings of diversity - a contemporary issue that is proving to be difficult to manage in global-North settings like Sw.

Another significant theme that this study highlights and where understandings from the global-South can potentially illuminate areas of current concerns in the global-North relate to conceptualizations related to language. This has particular significance since a monolingual ethos has contributed to making the "inclusion" of minorities an uphill task in contexts like Sw. American anthropologist Ruth Finnegan (2015) succulently reminded language scholars (in the global-North) at the end of her academic career, that there is need to pause and ask if "we" really know what, where and for whom language is. Decoloniality here represents a call for a new reflexivity that enables posing such uncomfortable questions that have the potential of illuminating non/mainstreamed ways-of-being-with-words. Going beyond both namism and academic branding and dealing with naturalistic datasets where the analysis builds upon theoretical framings is, we argue, key here.

Monolingual positions in the scholarship obscure the fact that most humans live lives engaging with and deploying resources from more than one language-variety (Gal and Irvine 1995; Hasnain et al. 2013; May 2014). A monolingual bias marks the global-North political discourse as compared to a much more fluid meaning-making interactional order in the In-dataset. In the latter, meaning-making is marked with the ways-of-beingwith-words that are common dimensions of IRL interactions across the globe. Having gained popularity in the global-North scholarship only recently, such fluidity is seen as novel and continues to be accounted for in terms of recent mobilities, urbanization, including digitalization; it is marked in terms of "super/hyper/urban-diversity", and "pluri/trans/metrolingualism or -languaging" (Blommaert 2015; Vertovec 2006). These glossed concepts build implicitly upon a non-marked mono-ethnic, monolingual norm. In addition to the fact that such scholarship is marked by reductionistic sloganism and academic branding (Pavlenko in press), a colonial hegemony underlies the continuing invisibility accorded to the patterned ways-of-being-with-words that mark languaging across time-space in the "rest of the world". 
Thus, identifying features of languaging across the datasets, and particularly from the global-South are significant. They mark important dimensions of human existence, and are not specific to contemporary times alone. In other words, our concern is related to making visible the dominating colonially framed monoglossic understandings of bounded language-varieties/modalities, including the monolingual ethos in the Sw-dataset. We call attention to the need for engaging with scholarship from and by global-South scholars with the intent of reconceptualizing languaging behavior and identity-positionings beyond boundaries. Thus, while a colonial linguacentrism, only in a limited manner, recognizes that routine ways of sense-making in digital (and IRL) settings are not only rich sites for research, but that languaging needs to be researched from points of departure where more than one language-variety are made analytically salient. "Dehegemonizing standard language" (Hasnain and Gupta 2002) points to a monolingual norm that exists primarily in global-North spaces from where the majority of language and identity scholars are referenced. While this situation is slowly changing, monolingual positions continue to remain non-marked, thus normalizing and legitimizing oppressive webs-of-understandings (Bagga-Gupta 2018).

Different types of chaining identified in the In-datasets constitute "normal communication and languaging". Chaining here builds upon oral, written, pictorial, embodied resources within Facebook and other media-types (Bagga-Gupta 2017b, c; Horowitz 2007; Jones and Hafner 2012). Furthermore, the medley of modalities, varieties, tools and embodiment illuminated in this study is similar to the complex, intricate ways in which oral-written-virtual-irl-embodied dimensions are chained and have been identified previously in other types of institutional settings (Bagga-Gupta 2017a, b, c, 2004; Gynne 2016; Messina Dahlberg 2015).

Like one of the first digital symbols, “@”, that heralded the digital era, the "\#” too has become a new letter/character in the contemporary netizens alphabetic tool-kit. The local-chaining in the Facebook pages where a symbolic representation i.e. \#, leaves one space (Twitter) and is presented in another (Facebook), not only constitutes contentchaining, but now becomes a marker of social media savviness. From sociocultural action and emic perspectives these dimensions of discourse constitute normal languaging. Symbolic units like "\#” and web-page URLs constitute fluid resources deployed by all individuals and communities that interface with digital mediaspaces. This means that being able to participate in contemporary political discourse is not contingent only upon access to digital technologies or peoples' skills in a specific language-variety or oral or written modality. It is the situated-distributed nature of specific kinds of knowledgefor instance what "\#" stands for or a string of alphabets strung together in a web page address-that are key dimensions of participation in mediascapes. Going beyond conventional language competencies, languaging here thus needs to be accounted for (in the analysis) in terms of the access that participants have to resources across digital mediascapes. The point that is salient is that it is not knowledge about a specific bounded language, or a specific writing system or membership in a particular nation-state that is significant in an overarching sense. Rather it is the ways-with-words that are contingent upon the ways-of-being, including the sociohistorical experiences of participants in a multitude of affinity spaces that are significant. 


\section{Abbreviations}

BJP: Bharatiya Janta Party; GSN: global-South and North; In: The Nation-State of India; ICR/C-R: initiation-commentresponse/comment-response; IRE: initiation-response-evaluation; IRL: in real life; Sw: The Nation-State of Sweden.

\section{Authors' contributions}

The first author, SBG, has in collaboration with the second author, AR, designed the study. Both authors have contributed equally to the creation of the datasets, its first level of analysis and its final analysis. The authors have collaborated through face-to-face meetings and by using social media platforms in weekly data-sessions and joint analysis. SBG and AR have had responsibility to do the initial elaborations of different sections of the paper. SBG has had overall responsibility for the study and the writing of the "Introduction" and "Discussion and reflections on ways-of-being-withwords across the global-South/North" sections. AR has been engaged in working on parts of the "Introduction" section and has commented on the development of the "Introduction" and "Discussion and reflections on ways-of-being-withwords across the global-South/North" sections. Both authors have worked closely in the writing and development of the "Discourse and mediascapes" section. The first author is the corresponding author. Both authors have read and approved the final manuscript.

\section{Authors' information}

Sangeeta Bagga-Gupta is Full Professor of Education at Jönköping University, Sweden, and Adjunct Professor 2016-2018 at AMU, Aligarh Muslim University, India. She conducted her doctoral studies at the multidisciplinary department of Communication Studies at Linköping University, Sweden and her post-doctoral studies at Gallaudet University in Washington DC, USA. Her multidisciplinary research focuses on communication broadly, identity, culture and learning from ethnographically framed, multi-scalar, sociocultural and decolonial framings. She is the scientific leader of the research group CCD, Communication, Culture and Diversity (http://www.ju.se/ccd) since the end of the 1990s, and is Director of the research milieu LPS, Learning Practices inside and outside Schools since 2016 (http://ju.se/en/research/research-groups/ learning-practices-inside-and-outside-school-lps.html).

Sangeeta Bagga-Gupta currently leads the large scale Swedish Research Council project PAL, Participation for all? (http://www.ju.se/ccd/pal). She publishes extensively in international peer-reviewed contexts and her latest edited books include:

Identity Revisted and Reimagined. Empirical and Theoretical Contributions on Embodied Communication Across Time and Space (2017 with Springer).

Marginalization Processes across Different Settings. Going beyond the Mainstream (2017 with Cambridge Scholars Publishing).

Aprameya Rao is a multimedia journalist and graduated from KC College, Mumbai, India. He has a Bachelors degree in economics and a Masters degree in Media Studies. He currently covers Indian politics and foreign relationships in his work for Firstpost.com.

\section{Author details}

'School of Education and Communication, Jönköping University, P.O. Box 1026, 55111 Jönköping, Sweden. ${ }^{2}$ B-007, Radhakrishna CHS, Mira Road, Thane 401107, India.

\section{Acknowledgements}

We would like to acknowledge the support of Dr. Guy Karnung in bringing clarity and precision to the screengrabs and figures that are used in this paper. We acknowledge the support of our institutions during the intensive periods of working on the research reported in this study.

Competing interests

The authors declare that they have no competing interests.

\section{Availability of data and materials}

The datasets used in the study presented in the paper are publicly available materials on the social media platform Facebook. The datasets are posts and comments etc. posted between the period 1 October and 15 November 2017 by four political parties, their members and participants on the internet. Webpages to the four pages are: https://www.facebook.com/BJP4India/. https://www.facebook.com/IndianNationalCongress/. https://www.facebook.com/moderaterna/. https://www.facebook.com/socialdemokraterna/.

\section{Ethics approval and consent to participate}

Not applicable.

\section{Funding}

We, the authors, have not received any specific funding for carrying out the research presented in this study.

\section{Publisher's Note}

Springer Nature remains neutral with regard to jurisdictional claims in published maps and institutional affiliations.

Received: 18 February 2018 Accepted: 18 April 2018

Published online: 02 May 2018 


\section{References}

Abu-Lughod, Janet. 1991. Before European hegemony. Oxford: Oxford University Press.

Andersson, Benedict. 1994. Imagined Communities. Reflections on the Origin and Spread of Nationalism. London: Verso.

Bagga-Gupta, Sangeeta. 2012. Challenging Understandings of Bilingualism in the Language Sciences from the Lens of Research that Focuses Social Practices. In Learning, Social Interaction and Diversity—Exploring School Practices, ed. Eva Hjörne, Geerdina van der Aalsvoort, and Guida de Abreu, 85-102. Rotterdam: Sense.

Bagga-Gupta, Sangeeta. 2013. The Boundary-Turn. Relocating Language, Identity and Culture Through the Epistemological Lenses of Time, Space and Social Interactions. In Alternative Voices: Researching Language, Culture and Identity, ed. Imtiaz Hasnain, Sangeeta Bagga-Gupta, and Shailendra Mohan, 28-49. Newcastle-upon-Tyne: Cambridge Scholars Publishing.

Bagga-Gupta, Sangeeta. 2014. Languaging:Ways-of-being-with-words across Disciplinary Boundaries and Empirical Sites In Language Contacts at the Crossroads of Disciplines, ed. Heli Paulasto, Lea Meriläinen, Helka Riionheimo, and Maria Kok, 89-130. Newcastle-upon-Tyne: Cambridge Scholars Publishing.

Bagga-Gupta, Sangeeta. 2017a. Language and Identity Beyond the Mainstream. Democratic and Equity Issues for and by Whom, Where, When and Why. Journal of the European Second Language Association. 11: 102-112. https://doi. org/10.22599/jesla.22.

Bagga-Gupta, Sangeeta. 2017b. Languaging and Isms of Reinforced Across Settings: Multidisciplinary Ethnographical Explorations. In ISMs of Oppression in Language Education, ed. Damian Rivers, and Karin Zotzmann, 203-229. Berlin: Mouton de Gruyter.

Bagga-Gupta, Sangeeta. 2017c. Going Beyond Oral-Written-Signed-Virtual Divides. Theorizing Languaging from Social Practice Perspectives. Writing \& Pedagogy. 9 (1): 49-75. https://doi.org/10.1558/wap.27046.

Bagga-Gupta, Sangeeta. 2018. Learning Languaging Matters. Contributions to a Turn-on-Turn Reflexivity. In Reconceptualizing Conceptions between Language, Learning and Literacy, ed. Sangeeta Bagga-Gupta, Anne Golden, Lars Holm, Helle Laursen, and Anne Pitkänen-Huhta. Rotterdam: Springer.

Bagga-Gupta, Sangeeta. 1995. Human Development and Institutional Practices: Women, Child Care and the Mobile Creches. Linköping Studies in Arts and Sciences 130. Doctoral Dissertation. Sweden: Linköping University.

Bagga-Gupta, Sangeeta, Aase L. Hansen, and Julie Feilberg (eds.). 2017. Identity Revisited and Reimagined. Empirical and Theoretical Contributions on Embodied Communication Across Time and Space. Rotterdam: Springer.

Bagga-Gupta, Sangeeta and Giulia Messina Dahlberg. 2018. Meaning-Making or Heterogeneity in the Areas of Language and Identity? The Case of Translanguaging and Nyanlända Across Time and Space. International Journal of Multilingualism.

Bali, Aasita and Jagan, Shivani. 2017. Use of Social Media in India and Political Communication. International Journal of Humanities and Social Science Studies IJHSSS, 243-253. http://oaji.net/articles/2017/1115-1486537686.pdf. Accessed 28/1 2018

Berger, Peter L., and Thomas Luckmann. 1966. The Social Construction of Reality. A Treatise in the Sociology of Knowledge. New York: Penguin.

Bhabha, Homi. 1994. The Location of Culture. London: Routledge.

Blommaert, 2015. Commentary: Superdiversity Old and New. Language \& Communication. https://doi.org/10.1016/j. langcom.2015.01.003.

Bucholtz, Mary, and Kira Hall. 2005. Identity and Interaction: A Sociocultural Linguistic Approach. Discourse Studies 74-5: 585-614.

Clifford, James. 1997. Routes: Travel and Translation in the Late Twentieth Century. Cambridge: Harvard University Press.

Comaroff, John, and Jean Comaroff. 2009. Ethnicity, Inc.. Chicago: University of Chicago Press.

Connell, Raewyn. 2014. Using Southern Theory. Decolonizing Social Thought in Theory, Research and Application. Planning Theory. 132: 201-223. https://doi.org/10.1177/1473095213499216.

Crystal, David. 2011. Internet Linquistics. New York: Routledge.

Finnegan, Ruth. 2015. Where is Language? An Anthropologist's Questions on Language, Literature and Performance. London and New York: Bloomsbury Academic.

Flewitt, Rosie, Regine Hampel, Mirjam Hauck, and Lesley Lancaster. 2009. What are Multimodal Data and Transcription? In The Routledge Handbook of Multimodal Analysis, ed. Carey Jewitt, 40-53. London: Routledge.

Gal, Susan, and Judith Irvine. 1995. The Boundaries of Languages and Disciplines: How Ideologies Construct Difference. Social Research 62: 967-1001.

Gee, Paul. 2005. Semiotic Social Spaces and Affinity Spaces: From the Age of Mythology to Today's Schools. In Beyond Communities of Practice: Language, Power and Social Context, ed. David Barton, and Karin Tusting, 214-232. Cambridge: Cambridge University Press.

Gleason, Philip. 1983. Identifying Identity: A Semantic History. The Journal of American History. 694: 910-931.

Goffman, Erwin. 1983. The Interaction Order. American Sociological Association, 1982 Presidential Address. American Sociological Review 481: 1-17.

Gramling, David. 2016. The Invention of Monolingualism. New York: Bloomsbury.

Gynne, Annaliina. 2016. Languaging, Learning and Identities in Glocal Educational Settings-The Case of Finnish Background Young People in Sweden. Doctoral Dissertation. Mälardalen University, Sweden.

Gynne, Annaliina, and Sangeeta Bagga-Gupta. 2015. Languaging in the Twenty-First Century. Exploring Varieties and Modalities in Literacies Inside and Outside Learning Spaces. Language and Education 29 (6): 509-526. https://doi.org $/ 10.1080 / 09500782.2015 .1053812$.

Hasnain, Imtiaz and Gupta, RS. 2002. From periphery to centre:Towards dehegemonizing standard language. Indian Linguistics 63 (1-4): 33-38

Hasnain, Imtiaz, Sangeeta Bagga-Gupta, and Shailendra Mohan (eds.). 2013. Alternative Voices: Researching Language, Culture and Identity. Newcastle-upon-Tyne: Cambridge Scholars Publishing.

Heath, ShirleyBrice. 1983. Ways with Words. Language, Life and Work in Communities and Classrooms. Cambridge: Cambridge University Press.

Horowitz, Rosalind. 2007. Talking Texts. How Speech and Writing Interact in School Learning. Mahwah: L. Erlbaum Associates. 
Ingstad, Benedicte, and Susan Reynolds Whyte (eds.). 2007. Disability in Local and Global Worlds. Berkeley: University of California Press.

Jewitt, Carey (ed.). 2009. The Routledge Handbook of Multimodal Analysis. London: Routledge.

Jones, Rodney, and Christoph Hafner. 2012. Understanding Digital Literacies. Routledge: A Practical Introduction Oxon.

Keating, Elisabeth, and Duranti Alessandro. 2011. Discourse and Culture. In Discourse Studies. A Multidisciplinary Introduction, ed. Teun A. Van Dijk, 331-356. London: Sage.

Khubchandani, Lachman Mulchand. 1997. Revisualizing Boundaries: A Plurilingual Ethos, vol. 3. New Dehli: Sage Publications.

Landri, Paolo, and Esxter Neuman. 2014. Introduction. Mobile Sociologies of Education. European Educational Research Journal. 131: 1-8.

Lave, Jean, and Etienne Wenger. 1999. Situated learning. Legitimate Peripheral Participation. Cambridge: Cambridge University Press.

Linell, Per. 2009. Rethinking Language, Mind, and World Dialogically Interactional and Contextual Theories of Human Sensemaking. Charlotte: Information Age Publishing.

Makoni, Sinfree B. 2012. A Critique of Language, Languaging and Supervernacular. Muitas Vozes. 12: 189-199.

Maldonado-Torres, Nelson. 2011. Thinking through the Decolonial Turn: Post-continental Interventions in Theory, Philosophy, and Critique-An Introduction. Transmodernity: Journal of Peripheral Cultural Production of the Luso-Hispanic. World 12: 1-15.

May, Stephan (ed.). 2014. The Multilingual Turn. Implications for SLA, TESOL, and Bilingual Education. London and New York: Routledge.

Mehan, Hugh. 1979. Learning Lessons. Social Organization in the Classroom. Harvard: Harvard University Press.

Messina Dahlberg, Giulia. 2015. Languaging in Virtual Learning Sites: Studies Of Online Encounters in the LanguageFocused Classroom. Doctoral Dissertation. Örebro Studies in Education 49. Sweden: Örebro University.

Mignolo, Walter. 2012. Local Histories/Global Designs. Coloniallity, Subaltern Knowledges and Border Thinking. New Jersey: Princeton University Press.

Narasimhamurthy, N. 2014. Use and Rise of Social Media as Election Campaign Medium in India. International Journal of Interdisciplinary and Studies IJIMS. http://www.ijims.com/uploads/7f33858cd2c22045d277A27.pdf. Assessed 28/1 2018.

Narayan, Sunetra Sen, and Shalini Narayanan. 2016. India Connected. Mapping the Impact of NEW Media. Delhi: Sage.

Paul, Chilton, and Schaffner Christina. 2011. Discourse and Politics. In Discourse Studies. A Multidisciplinary Introduction, ed. Teun A. Dijk, 303-330. London: Sage.

Pavlenko, Aneta. 2003. "I Never Knew I Was a Bilingual": Reimagining Teacher Identities in TESOL. Journal of Language, Identity \& Education. 2 (4): 251-268.

Pavlenko, Aneta. 2018. Superdiversity and Why it isn't: Reflections on Terminological Innovation and Academic Branding. In Sloganizations in language education discourse, eds. S Breidbach, L. Küster and B. Schmenk, Bristol. UK: Multilingual Matters (in press)

Quijano, Anibal. 2000. Coloniality of Power, Eurocentrism, and Latin America. Nepantla: Views from South. 1 (3): 533-580.

Rahul, K. 2016. Use of New Media in Indian Political Campaigning System. Journal of Political Sciences and Public Affairs. 4: 204. https://doi.org/10.4172/2332-0761.10002046.

Rao, Aprameya. 2017. Social Media Communication in the Demonetisation Era: A Study of the Official Facebook Pages of the Two Largest National Political Parties in India. Unpublished Masters Dissertation. India: University of Mumbai.

Rivers, David J., and Karin Zotzmann (eds.). 2017. ISMs in Language Education. Oppression, Intersectionality and Emancipation. Boston: De Gruyter Mouton.

Saleem, Awais, and McDowell D. Stephan. 2016. Social Media and Indian Politics in the Global Context: Promise and Implicaitons. In India Connected. Mapping the Impact of New Media, ed. Sunetra Sen Narayan, and Shalini Narayan, 79-105. Delhi: Sage.

Säljö, Roger. 2010. Digital Tools and Challenges to Institutional Traditions of Learning: Technologies, Social Memory and the Performative Nature of Learning. Journal of Computer Assisted learning. 261: 53-64.

Santos, Boaventura de Souza. 2014. Epistemologies of the South: Justice against Epistemicide. Boulder: Paradigm Publishers.

Savransky, Martin. 2017. A Decolonial Imagination: Sociology, Anthropology and the Politics of Reality. Sociology 511: $11-26$.

Schroeder, Ralph. 2016. Rethinking Digital Media and Political Change Convergence. The International Journal of Research into Media Technologies. https://doi.org/10.1177/1354856516660666.

Scollan, Ron, and Susan W. Scollan. 2004. Nexus Analysis. Discourse and the Emerging Internet. London: Routledge.

Sheller, Mimi, and John Urry. 2006. The new Mobilities Paradigm. Environment and Planning. 382: 207-226. https://doi. org/10.1068/a37268.

Srivastava, Jatin, and Roy Enakshi. 2016. Theoretical Perspectives: Issues in the Indian New Media Environment. In India Connected Mapping the impact of New Media, ed. Narayan Sunetra Sen, and Narayanan Shalini, 20-46. Delhi: Sage.

Vertovec, Steve. 2006. The Emergence of Super-diversity in Britain. Oxford: Centre of Migration, Policy and Society. University of Oxford.

Vygotsky, Lev S. 1962. Thought and Language. Cambridge: MIT Press.

Wertsch, James. 1998. Mind as Action. Oxford: Oxford University Press.

Wetherell, Margaret. 2010. The Field of Identity Research. In The Sage Handbook of Identities, ed. Margaret Wetherell, and Mohanty Chandra Talpade, 3-26. London: Sage Publications.

Wetherell, Margaret, and Chandra Talpade Mohanty (eds.). 2010. The Sage Handbook of Identities. London: Sage

Publications.

Wolcott, Harry. 1999. Ethnography. A Way of Seeing. Walnut Creek: AltaMira. 